\title{
Simple Formulas for Estimating a Lumped Parameter Model to Reproduce Impedances of End-Bearing Pile Foundations
}

\author{
Morici Michele $^{1}$, Minnucci Lucia ${ }^{2}$, Carbonari Sandro², Dezi Francesca ${ }^{3}$, Leoni Graziano ${ }^{1}$ \\ ${ }^{1}$ SAAD, University of Camerino, Ascoli Piceno, Italy \\ ${ }^{2}$ DICEA, Università Politecnica delle Marche, Ancona, Italy \\ ${ }^{3}$ DESD, University of San Marino, San Marino, Republic of San Marino
}

ABSTRACT: The paper presents simple formulas to evaluate parameters of a lumped system reproducing the frequency-dependent dynamic stiffness of end-bearing pile foundations. The model can be implemented in commercial finite element software and allows performing inertial soil-structure interaction analyses of structures considering the coupled roto-translational, vertical and torsional behaviour of the soil-foundation system. Pile groups arranged in a square layout are considered; the soil profile is constituted by a homogeneous deformable soil layer overlying a bedrock where piles are socked for a fixed length. Formulas are calibrated with a nonlinear least square procedure, based on data provided by an extensive non-dimensional parametric analysis of the soil-foundation systems, performed with a Winkler's type model, previously developed by the authors, which assumes soil and piles to behave linearly. Firstly, the suitability of the adopted numerical tools in capturing the dynamic stiffness of end-bearing foundations is proven. Then, capabilities of the proposed formulas in estimating parameters of the best lumped systems are shown, and, for some case studies, comparisons of non-null terms of the impedance matrix obtained through the best lumped system, the one computed through the formulas, and the impedances resulting from the dynamic analyses, are presented. Finally, some applications of the proposed formulas in the framework of the seismic soil-structure interaction analysis of bridges are shown to demonstrate the capability of the adopted lumped system and the formula efficiency in assuring a reliable evaluation of the superstructure seismic response, with respect to that obtained from a more rigorous approach.

Keywords: End-bearing pile groups, foundation impedances, inertial analysis, lumped parameter model, soil-structure interaction

\section{INTRODUCTION}

The role of Soil-Structure Interaction (SSI) in the dynamic response of structural systems has been well addressed in the literature, which nowadays provides sufficient and useful information concerning situations (e.g. seismic scenarios, foundation and structural typologies) in which SSI has to be included in the evaluation of the structural response [1-8]. Nevertheless, SSI is usually neglected in the design because of the complexity of analytical and numerical procedures involved in its evaluation. Indeed, both the direct or the sub-structure approach, recognised in the literature as classical analysis methodologies, are characterised by important computational effort requiring the use of sophisticated software and the definition of a great number of parameters (e.g. $[9,10])$ or the application of stepped procedures involving the use of specific tools (e.g. [11]). 
From a practical point of view, the substructure approach is more attractive. This consists in studying separately the soil-foundation sub-system, subjected to the propagation of seismic waves, and the superstructure sub-system resting on suitable dynamic compliant restraints and subjected to the Foundation Input Motion (FIM), which differs from the free-field motion at the soil outcrop. The approach is classically adopted for linear systems but can be suitably employed also to include effects of superstructure non-linearity by maintaining the assumption of linearity for the soilfoundation system [e.g. 3, 8]. This is acceptable if foundations are designed to avoid the pile plasticization, if local pile-soil gaps are neglected, and if a linear equivalent model is adopted for the soil to account for possible mechanical nonlinearities. For soil conditions governed by high nonlinear phenomena and permanent deformations, the approach cannot be used.

The substructure approach can be remarkably simplified by assuming the FIM to be equal to the free-field one at surface. Despite kinematic effects of SSI for piled foundations has been widely recognized to make the FIM different from the free-field motion, there are frequency ranges in which kinematic effects may be considered of minor importance; the latter depend strongly on the relative pile rigidity, pile slenderness, soil layering, pile spacing and the number of piles. Overall, these frequency ranges $(0 \div f)$ increase by increasing the number of piles and the pile spacing and by decreasing the relative pile rigidity [12]. In conjunction with above considerations, input actions characterized by low frequency content contribute to reduce the importance of kinematic effects [13]. A second important task that needs simplification to make SSI analyses more familiar to professional engineers, is the derivation of the frequency-dependent dynamic impedances of the soil-foundation systems and their incorporation in time domain analyses. Lumped Parameter Models (LPMs) [14], obtained by assembling springs, masses and dashpots, are usually adopted to this purpose. However, dynamic impedances must be known, determined through not familiar numerical tools, and the most suitable LPM has to be selected among those available in the literature, and calibrated to best reproduce impedances of the specific foundation (e.g. [15-19]).

In line with the need of simplification of SSI analysis procedures, the authors recently presented a LPM for the approximation of the dynamic impedances of pile groups and provided closed-form formulas for estimating parameters of the model for foundations in homogeneous soil deposits [20]. The efficiency of the proposed model in reproducing impedances of pile foundations in performing inertial SSI analyses was further demonstrated in [21] where it was used, in addition with more sophisticated approaches, to address the seismic response of bridge piers, discussing issues such as the soil damping modelling and the LPM complexity.

This paper extends results of the research presented in [20] for piled foundations in homogenous soils, proposing new formulas for estimating components of the LPM to approximate the dynamic stiffness of end-bearing single piles and pile groups. These are characterised by a different number of piles crossing a deformable shallow soil layer of different stiffness and embedded for three diameters into an underlying bedrock. The lumped model can capture the coupled rototranslational, vertical and torsional behaviour that characterise the response of pile groups. Formulas for the evaluation of the system parameters are evaluated through a nonlinear regression of data resulting from a comprehensive non-dimensional parametric investigation. The dataset is obtained by performing dynamic analyses of soil-foundation systems in homogenous soil deposits by means of the numerical model developed by Dezi et al. [22], which provides impedances of pile groups, and by optimising parameters of the lumped models through a linear regression approach. Formulas, that may be implemented in simple spreadsheets, allow defining restraint systems that can be physically reproduced in common software for structural analysis, avoiding the (i) evaluation of the dynamic impedance functions and the (ii) LPMs selection and calibration 
process. The efficiency of the proposed formulas in assuring a reliable evaluation of the seismic response of bridge piers, with respect to that obtained from a more rigorous approach for the analysis of the SSI problem, are presented and discussed with reference to some case studies. In detail, the seismic SSI analysis of four bridge piers founded on different soils is performed and the proposed LPM, with parameters estimated by the proposed closed formulas, is adopted to simulate the soil-foundation dynamic behaviour. By assuming the FIM to be equal to the free-field motion, inertial interaction analyses are performed avoiding frequency domain analyses of the soilfoundation system. Results of the analyses are compared with those achieved through a rigorous approach considering the actual frequency-dependent soil-foundation impedances and FIM. Results of fixed base applications are included to highlight the significance of the SSI problem for the selected analysis cases.

\section{RECALL AND SUITABILITY OF ADOPTED TOOLS}

In this section the suitability of the numerical model adopted to build up the database of impedances used for the formulas regression, as well as the potentialities of the selected LPM in reproducing the dynamic stiffness of end-bearing pile groups are discussed.

\subsection{Numerical model for the soil-foundation dynamic analysis}

Impedances are obtained performing dynamic analyses of case studies through the numerical model developed by Dezi et al. [22]; piles are modelled with 2-node beam elements with third order and linear polynomials for the interpolation of transverse and longitudinal displacements, respectively, while the soil is assumed to be constituted by independent horizontal infinite viscoelastic layers. Displacement components of the soil are not physically included in the problem formulation since the soil-pile interaction and the radiation damping are taken into account in the frequency domain by means of elastodynamic Green's functions available in the literature for the plane strain problem [22-27]. The presence of a rigid cap is accounted for by constraining displacements of the pile heads. The model allows performing kinematic soil-foundation interaction analysis of pile groups with generic number of piles, layout and piles inclination and permits the derivation of the soil-foundation impedance matrix through the problem condensation on the rigid cap degrees of freedom. With reference to homogenous half spaces, the model was validated by the Authors comparing results with those obtained from 3D refined finite element models [22].

The model does not account for the vertical continuity of the soil medium and the interaction between layers is assured by piles. Thus, as well known for Winkler's type models implementing plane strain solutions, resonant frequencies and associated cut-off effects cannot be captured directly, unless empirical adjustments are adopted [28-31]. Above effects may become very important in the case of piles embedded in soil deposits overlying stiff strata (i.e. in presence of a high impedance contrast between layers); in above situations the cut-off frequency, namely the first resonance of the soil-pile foundation system, defines the frequency associated to the emerging of waves propagating in the medium. For frequencies below the cut-off one, the stiffness of the system is almost unaffected by the damping, which is practically only due to the material hysteretic contribution; near the cut-off frequency the stiffness tends to diminish drastically and damping increases rapidly due to the contribution of waves radiating into the medium (geometric damping). Beyond the cut-off frequency, the behaviour is similar to that obtained by assuming plane strain conditions for the waves propagation. Generally, the plane strain solution underestimates the real 
part of impedances and overestimates the imaginary part for frequencies below the cut-off ones $[32,33]$. However, by increasing the pile slenderness ratio or the pile-soil modulus ratio, cut-off effects reduce and models implementing the plane strain solutions become more reliable in estimating the soil-foundation dynamic impedances.

Taking into account the investigated soil-foundation layout (Figure 1a) and the variability of geometric and mechanical parameters that will be considered in the sequel for the formulas calibration, some applications are herein presented to show the suitability of the model proposed in estimating impedances of the selected end-bearing foundations. Potential critical scenarios, constituted by low pile slenderness ratios and high impendence contrasts between the deformable layer and the bedrock are included. Components of impedance matrices obtained with the numerical model developed by the Authors are compared with those obtained from a refined 3D finite element model, developed in ANSYS [34]. In details, 16 analysis cases are considered combining non-dimensional geometric and mechanical properties of soils and foundations reported in Figure 1b. The latter descend from a formal application of the Buckingam's theorem [35].

Taking into account the double symmetry of case studies, and considering the reference system frame of Figure 1a, the non-dimensional soil-foundation impedance matrix assumes the form

$$
\Pi\left(a_{0}\right)=\left[\begin{array}{cccccc}
\Pi_{x}\left(a_{0}\right) & 0 & 0 & 0 & \Pi_{x-r y}\left(a_{0}\right) & 0 \\
& \Pi_{x}\left(a_{0}\right) & 0 & -\Pi_{x-r y}\left(a_{0}\right) & 0 & 0 \\
& & \Pi_{z}\left(a_{0}\right) & 0 & 0 & 0 \\
& & & \Pi_{r y}\left(a_{0}\right) & 0 & 0 \\
& & & & \Pi_{r y}\left(a_{0}\right) & 0 \\
& & & & & \Pi_{r z}\left(a_{0}\right)
\end{array}\right]
$$

where

$$
\begin{array}{ll}
\Pi_{i}\left(a_{0}\right)=\frac{\mathfrak{I}_{i}}{\rho_{s} V_{s}^{2} d} & \text { with } i=x, z \\
\Pi_{r i}\left(a_{0}\right)=\frac{\mathfrak{I}_{r i}}{\rho_{s} V_{s}^{2} d^{3}} & \text { with } i=x, z \\
\Pi_{x-r y}\left(a_{0}\right)=\frac{\mathfrak{I}_{x-r y}}{\rho_{s} V_{s}^{2} d^{2}} &
\end{array}
$$

are the non-dimensional translational, rotational and coupled roto-translational impedances of the soil-foundation systems, obtained starting from the relevant dimensional components $\mathfrak{I}_{i}, \mathfrak{J}_{r i}$ and $\mathfrak{J}_{x-r y}$ (with $i=x, z$ ). In Equations (1) and (2), $a_{0}=\omega d / V_{s}$ is non-dimensional circular frequency.

The refined 3D model is developed adopting 8-node linear brick elements to model a quarter of a cylindrical soil portion with radius $R$ and height $H$ satisfying conditions $R / d=70$ and $H / d=70$ (Figure 2a). A viscoelastic material is adopted for the soil and infinite elements, based on the formulation by Kaljevic et al. [36], are placed at the boundaries to simulate the radiation condition, absorbing most of the outgoing waves. Piles are modelled with 2-node cubic beam elements and their physical dimensions are considered removing the relevant soil cylinders (Figure $2 b$ ). The beam-solid coupling is enforced exploiting potentials of the adopted software. 


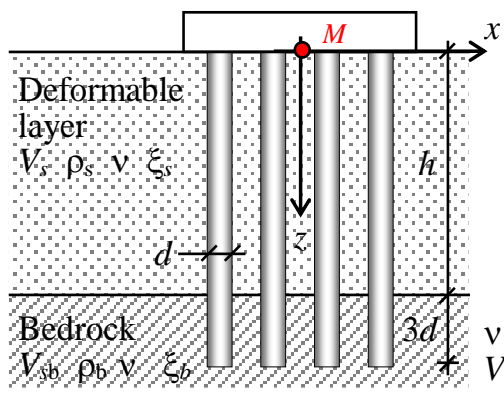

(a)

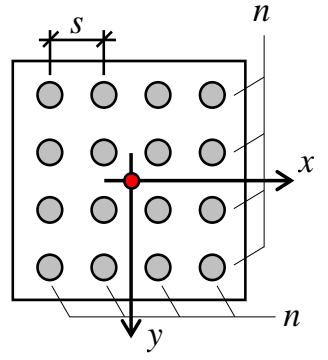

$=0.4 \quad \xi_{s}=5 \% \quad \xi_{b}=2 \%$

$V_{s \mathrm{~b}}=800 \mathrm{~m} / \mathrm{s} \rho_{b}=2.5 \mathrm{Mg} / \mathrm{m}^{3}$

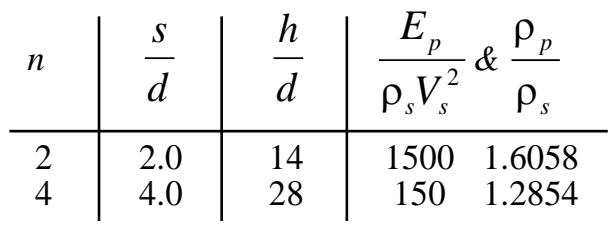

(b)

Figure 1. (a) Soil-foundation layouts and (b) selection of geometric and mechanical parameters generating the analysis cases

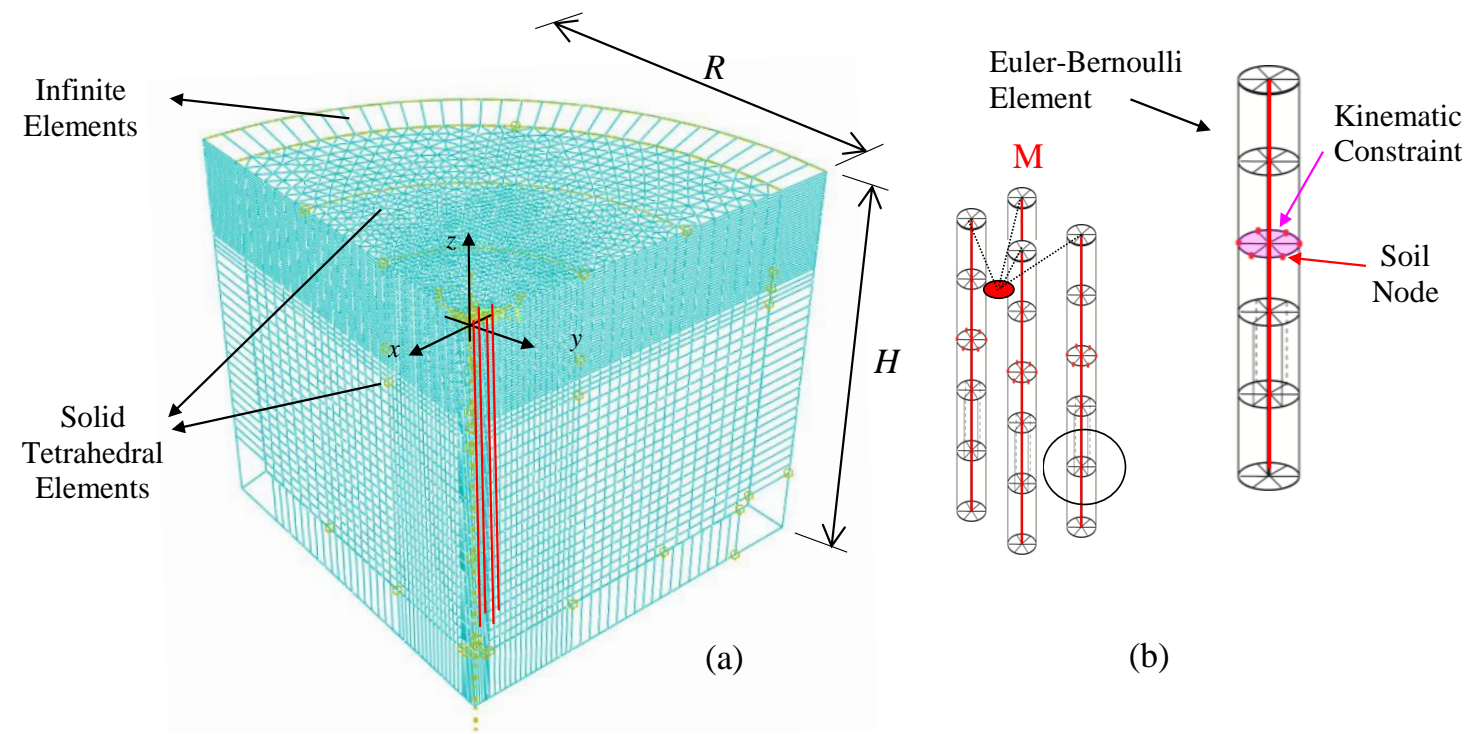

Figure 2. 3D refined finite element model

Piles are connected at the head by a rigid constraint (Figure 2b) and meshing criteria aimed at obtaining an as much as possible structured mesh and assuring a sufficient number of nodes per wavelength are adopted. Some accuracy analyses are preliminarily performed to define the mesh dimension in order to balance results reliability with computational efforts; the selected mesh dimension assures that the propagation of waves with frequency up to $15 \mathrm{~Hz}$ is well captured. As for the model proposed by the Authors, a highly refined vertical mesh is used for the pile $(0.5 \mathrm{~m})$, since the computational effort is overall very low.

Soil-foundation impedances from the refined 3D model are obtained by imposing unit steady harmonic displacements at the fully restrained master node and evaluating the relevant reaction forces; symmetry or antisymmety conditions are imposed at boundaries, depending on the investigated component of the impedance matrix.

For the sake of brevity only some results obtained from the applications are shown in detail in the sequel, comparing impedances obtained from the model by Dezi et al. [22] and the ANSYS model; the latter, which has fewer simplifying hypotheses with respect to the former, is considered 
to provide more precise results with respect to the exact solution of the 3D linear wave propagation problem.

Figure 3 refers to the non-dimensional real and imaginary parts of the translational, vertical, rotational and coupled roto-translational impedances of the $2 \times 2$ pile group with $s / d=4, h / d=14$ and different $E_{p} /\left(\rho_{s} V_{s}^{2}\right)$ ratios. Results of the 3D refined finite element model are reported with marks while continuous lines are used for results of the adopted model. Cut-off effects are evident in the horizontal, vertical and coupled roto-translational impedances, especially in the case of soft soils, while for stiff soils effects appear of less significance. Also, for the rotational impedance, cut-off effects do not modify sensibly the overall trends of both real and imaginary parts. From an engineering point of view, the numerical model developed by Dezi et al. is overall capable of reproducing the behaviour of soil-foundation systems evaluated through the 3D refined model in the frequency range $0 \div 10 \mathrm{~Hz}$, which may be considered of practical interest in earthquake engineering because it usually includes both the highest energy content of earthquakes and the fundamental frequencies of civil structures. However, the model is not able to capture local trends of impedances due to cut-off effects. The model underpredicts the actual horizontal stiffness in the case of stiff soils: this aspect is already known in the literature, for Winkler-type models [e.g. 37]. The latter issue appears to be of greater significance with respect to the cut-off induced phenomena.

Similarly, Figure 4 refers to the non-dimensional real and imaginary parts of the translational, vertical, rotational and coupled roto-translational impedances of the $4 \times 4$ pile group with $s / d=2$, $h / d=28$ and different $E_{p} /\left(\rho_{s} V_{s}^{2}\right)$ ratios. As expected, in view of the higher soil layer thickness overlying the bedrock, cut-off effects are less important and only clearly evident for the coupled roto-translational behaviour of the selected case studies.
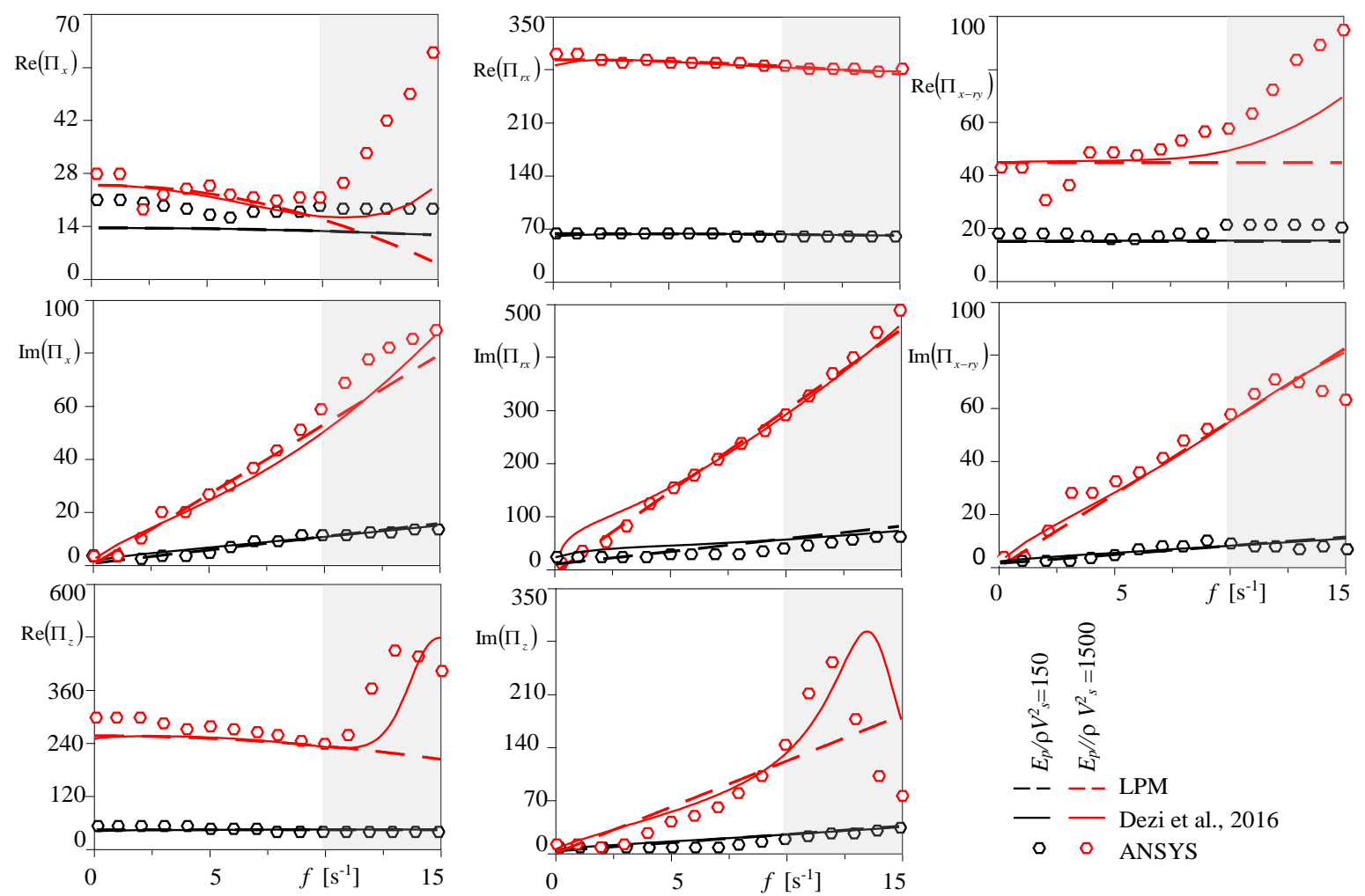

Figure 3. Impedances of $2 \times 2$ pile groups with s/d $=4, h / d=14$ and different $E_{p} / E_{s}$ ratios 

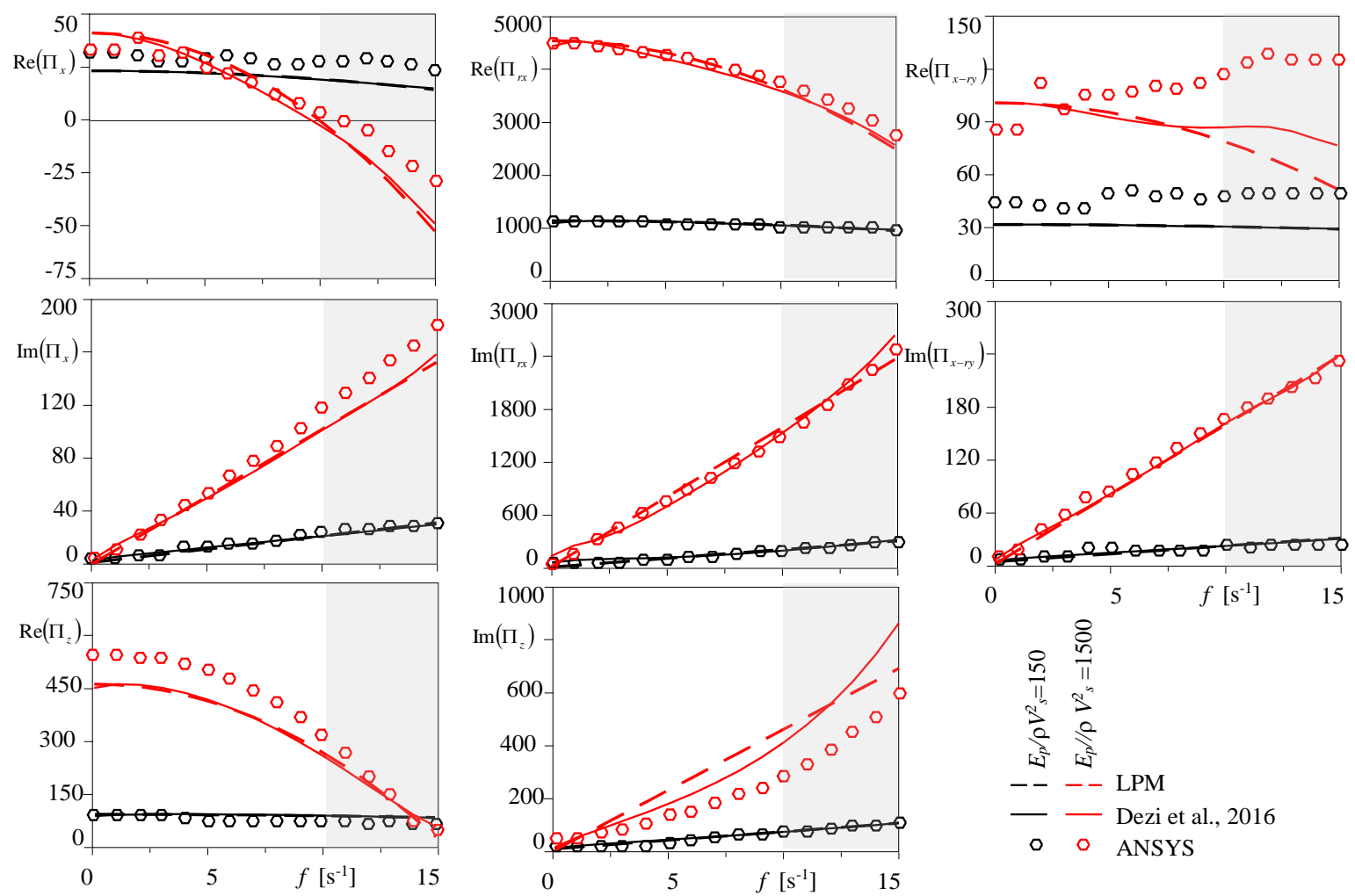

Figure 4. Impedances of $4 \times 4$ pile groups with s/d $=2, h / d=28$ and different $E_{p} / E_{s}$ ratios

With reference to the horizontal impedance, the adopted model [22] slightly underpredicts the response of the 3D model in the case of stiff soils and overpredicts that relevant to soft soils, in the low frequency range. Greatest inaccuracies affect the vertical stiffness in the case of soft soils and the coupled roto-translational one, for both stiff and soft soils; in these cases, the response provided by the Authors' model differs of about $20 \%$ from that of the 3D refined solid model.

Considering ANSYS model results $(A N S$ ) as benchmarks, overall errors (within the range $0 \div 10$ $\mathrm{Hz}$ ) of the proposed model $(D)$ can be computed by means of

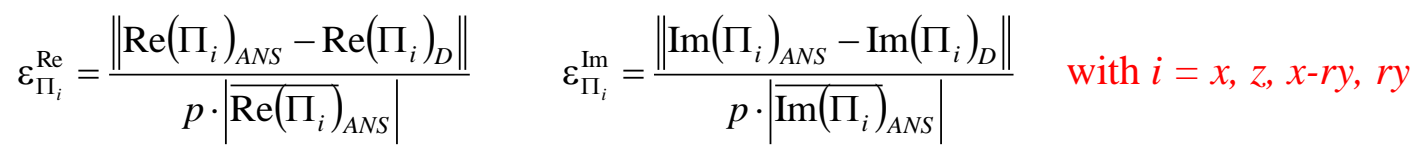

for real and imaginary parts of impedance functions $\Pi_{i}$. In Equations $(3), \cdot\left(\Pi_{i}\right)_{A N S}$ are the mean values of the $i$-th component of the impedance matrix obtained from the ANSYS model and $p=11$ is the number of frequencies over which impedances are evaluated. Errors resulting from Equations (3) are collected in Table 1 for the full set of considered cases. Data relevant to analysis cases shown in Figures 3 and 4 (highlight in Table 1) provide a relation between the errors amounts and trends of impedances from the two models in the entire frequency range and make it possible to interpret results from all the set of applications. Overall imaginary parts present higher errors than real ones, especially the vertical component. Anyway, most cases are affected by errors below $10 \%$. 
Table 1. Overall percentage errors ([\%]) between real and imaginary parts of impedances from Equations (3)

\begin{tabular}{|c|c|c|c|c|c|c|c|c|c|c|c|}
\hline \multirow{2}{*}{$n$} & \multirow{2}{*}{$s / d$} & \multirow{2}{*}{$h / d$} & \multirow{2}{*}{$E_{p} /\left(\rho_{s} V_{s}^{2}\right)$} & \multicolumn{2}{|c|}{$\Pi_{x}$} & \multicolumn{2}{|c|}{$\Pi_{r y}$} & \multicolumn{2}{|c|}{$\Pi_{x-r y}$} & \multicolumn{2}{|c|}{$\Pi_{z}$} \\
\hline & & & & $\operatorname{Re}$ & $\mathrm{Im}$ & $\mathrm{Re}$ & $\mathrm{Im}$ & $\operatorname{Re}$ & $\mathrm{Im}$ & $\operatorname{Re}$ & $\mathrm{Im}$ \\
\hline \multirow{8}{*}{2} & \multirow{4}{*}{2} & \multirow{2}{*}{14} & 150 & 7.3 & 8.0 & 2.9 & 23.2 & 3.3 & 8.7 & 3.2 & 36.0 \\
\hline & & & 1500 & 3.1 & 4.0 & 1.0 & 4.2 & 3.6 & 5.2 & 3.5 & 13.6 \\
\hline & & \multirow{2}{*}{28} & 150 & 7.0 & 4.1 & 2.8 & 21.3 & 3.2 & 4.6 & 5.0 & 9.1 \\
\hline & & & 1500 & 1.7 & 3.6 & 0.8 & 4.3 & 2.5 & 3.7 & 0.7 & 2.1 \\
\hline & \multirow{4}{*}{4} & \multirow{2}{*}{14} & 150 & 9.1 & 7.5 & 1.2 & 25.0 & 5.3 & 10.0 & 4.0 & 39.0 \\
\hline & & & 1500 & 4.5 & 5.0 & 0.6 & 4.5 & 4.4 & 4.2 & 3.2 & 8.9 \\
\hline & & \multirow{2}{*}{28} & 150 & 8.9 & 3.3 & 1.1 & 16.0 & 6.2 & 9.4 & 5.0 & 9.4 \\
\hline & & & 1500 & 3.9 & 4.9 & 1.0 & 3.9 & 3.3 & 2.8 & 2.5 & 8.5 \\
\hline \multirow{8}{*}{4} & \multirow{4}{*}{2} & \multirow{2}{*}{14} & 150 & 8.3 & 8.5 & 1.0 & 16.5 & 7.9 & 12.6 & 5.3 & 31.6 \\
\hline & & & 1500 & 12.3 & 6.3 & 1.6 & 4.8 & 7.3 & 6.5 & 9.2 & 20.3 \\
\hline & & \multirow{2}{*}{28} & 150 & 7.6 & 4.2 & 0.7 & 4.8 & 9.8 & 8.1 & 5.6 & 9.8 \\
\hline & & & 1500 & 5.5 & 4.2 & 0.7 & 1.8 & 5.4 & 2.5 & 5.1 & 15.1 \\
\hline & \multirow{4}{*}{4} & \multirow{2}{*}{14} & 150 & 12.5 & 11.0 & 1.2 & 27.5 & 10.9 & 20.7 & 8.0 & 37.3 \\
\hline & & & 1500 & 16.9 & 7.8 & 1.5 & 7.6 & 15.1 & 11.6 & 9.1 & 13.8 \\
\hline & & \multirow{2}{*}{28} & 150 & 11.9 & 6.7 & 3.3 & 3.9 & 15.6 & 28.6 & 8.8 & 9.6 \\
\hline & & & 1500 & 16.3 & 7.5 & 4.0 & 14.4 & 11.3 & 10.3 & 23.8 & 19.7 \\
\hline
\end{tabular}

\subsection{Lumped Parameter Model}

The lumped model presented by Carbonari et al. [20] and depicted in Figure 5 is considered in this work. As already stated, because of the symmetry of the system, the foundation is characterised by uncoupled vertical and torsional responses, whereas horizontal displacements and relevant rotations are coupled as usual for deep foundations. Furthermore, the double symmetry of the system makes the roto-translational responses uncoupled between planes $x z$ and $y z$, too. The adopted LPM reflects above aspects and is obtained assembling independent sub-LPMs, as presented in Figure 5, which refer the uncoupled behaviours of the soil-foundation systems. The square layout of the pile group implies that the whole system is characterized by 18 parameters, namely: translational and rotational masses, lumped at the master node of the rigid cap (4 parameters), elastic and viscous constants that define the relevant spring-dashpot elements also applied at the master node ( 8 parameters) and additional eccentric springs, dashpots and masses ( 3 parameters), connected to the master node by rigid links of different lengths (3 parameters). Eccentric components are introduced to catch the coupling between the rotation and the translation in $x$ and $y$ directions.

Following a formal non-dimensional approach [35] for the formulation of the system impedance matrix, the following expressions hold for parameters of the lumped model

$$
\begin{aligned}
& k_{i}=\rho_{s} V_{s}^{2} d\left(\Omega_{1}-\Omega_{4} \frac{d}{h_{k i}}\right) \quad m_{i}=\rho_{s} d^{3}\left(\Omega_{2}-\Omega_{5} \frac{d}{h_{m i}}\right) \quad c_{i}=\rho_{s} V_{s} d^{2}\left(\Omega_{3}-\Omega_{6} \frac{d}{h_{c i}}\right) \quad(4 \mathrm{a}, \mathrm{b}, \mathrm{c}) \\
& k_{i h}=\Omega_{4} \frac{\rho_{s} V_{s}^{2} d^{2}}{h_{k i}} \quad m_{i h}=\Omega_{5} \frac{\rho_{s} d^{4}}{h_{m i}} \quad c_{i h}=\Omega_{6} \frac{\rho_{s} V_{s} d^{3}}{h_{c i}}
\end{aligned}
$$



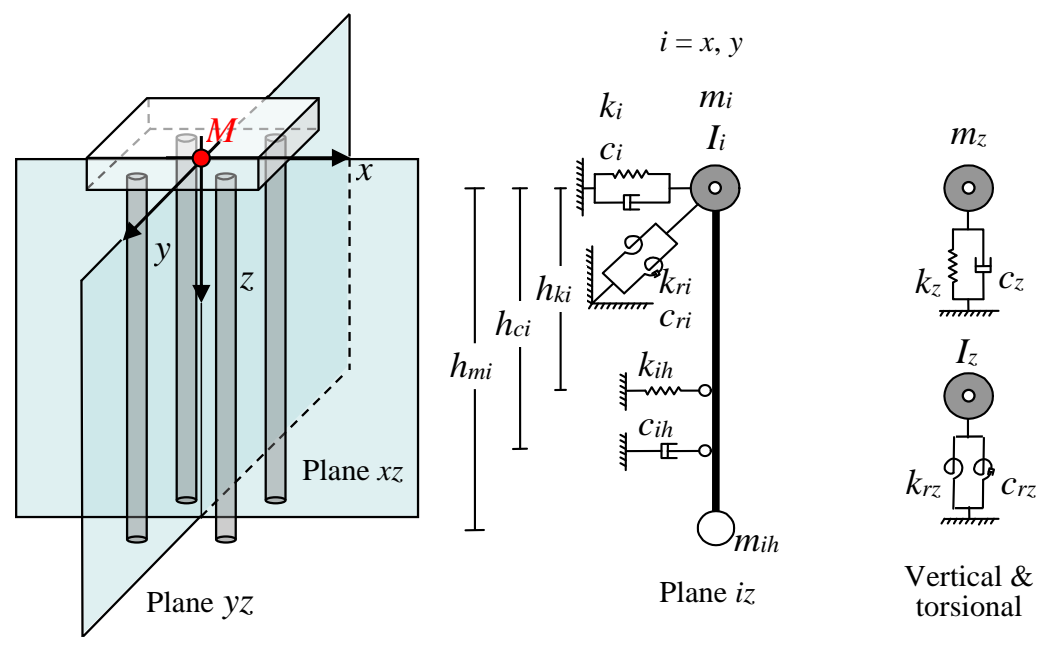

Figure 5. Assemblage of uncoupled LPMs

$$
\begin{array}{lll}
k_{r i}=\rho_{s} V_{s}^{2} d^{3}\left(\Omega_{7}-\Omega_{4} \frac{h_{k i}}{d}\right) & I_{i}=\rho_{s} d^{5}\left(\Omega_{8}-\Omega_{5} \frac{h_{m i}}{d}\right) & c_{r i}=\rho_{s} V_{s} d^{4}\left(\Omega_{9}-\Omega_{6} \frac{h_{c i}}{d}\right) \\
k_{z}=\Omega_{10} \rho_{s} V_{s}^{2} d & m_{z}=\Omega_{11} \rho_{s} d^{3} & c_{z}=\Omega_{12} \rho_{s} V_{s} d^{2} \\
k_{r z}=\Omega_{13} \rho_{s} V_{s}^{2} d^{3} & I_{z}=\Omega_{14} \rho_{s} d^{5} & c_{r z}=\Omega_{15} \rho_{s} V_{s} d^{4}
\end{array}
$$

where $\Omega i(i=1 \ldots 15)$ are the non-zero non-dimensional components of the lumped system impedance matrix

$$
\tilde{\mathbf{\Pi}}\left(\mathbf{\Omega}, a_{0}\right)=\overline{\mathbf{K}}(\mathbf{\Omega})-a_{0}^{2} \overline{\mathbf{M}}(\mathbf{\Omega})+i a_{0} \overline{\mathbf{C}}(\mathbf{\Omega})
$$

In Equation (5),

$$
\begin{aligned}
& \overline{\mathbf{K}}=\left[\begin{array}{cccccc}
\Omega_{1} & 0 & 0 & 0 & \Omega_{4} & 0 \\
& \Omega_{1} & 0 & -\Omega_{4} & 0 & 0 \\
& & \Omega_{10} & 0 & 0 & 0 \\
& & & \Omega_{7} & 0 & 0 \\
& \text { sym } & & & \Omega_{7} & 0 \\
& & & & & \Omega_{13}
\end{array}\right] \quad \overline{\mathbf{M}}=\left[\begin{array}{cccccc}
\Omega_{2} & 0 & 0 & 0 & \Omega_{5} & 0 \\
& \Omega_{2} & 0 & -\Omega_{5} & 0 & 0 \\
& & \Omega_{11} & 0 & 0 & 0 \\
& & & \Omega_{8} & 0 & 0 \\
& & & & &
\end{array}\right. \\
& \overline{\mathbf{C}}=\left[\begin{array}{cccccc}
\Omega_{3} & 0 & 0 & 0 & \Omega_{6} & 0 \\
& \Omega_{3} & 0 & -\Omega_{6} & 0 & 0 \\
& & \Omega_{12} & 0 & 0 & 0 \\
& & & \Omega_{9} & 0 & 0 \\
& \text { sym } & & & \Omega_{9} & 0 \\
& & & & & \Omega_{15}
\end{array}\right]
\end{aligned}
$$

Parameters $h_{k i}, h_{c i}, h_{m i}$ appearing at the right-hand side of Equations (4) are arbitrarily chosen according to the following conditions 


$$
\left\{\begin{array}{l}
\operatorname{sgn} h_{k i}=\operatorname{sgn} \Omega_{4} \\
\left|\frac{\Omega_{4}}{\Omega_{1}}\right| d \leq\left|h_{k i}\right| \leq\left|\frac{\Omega_{7}}{\Omega_{4}}\right| d
\end{array}\right.
$$

$$
\left\{\begin{array}{l}
\operatorname{sgn} h_{m i}=\operatorname{sgn} \Omega_{5} \\
\left|\frac{\Omega_{5}}{\Omega_{2}}\right| d \leq\left|h_{m i}\right| \leq\left|\frac{\Omega_{8}}{\Omega_{5}}\right| d
\end{array}\right.
$$

$$
\left\{\begin{array}{l}
\operatorname{sgn} h_{c i}=\operatorname{sgn} \Omega_{6} \\
\left|\frac{\Omega_{6}}{\Omega_{3}}\right| d \leq\left|h_{m i}\right| \leq\left|\frac{\Omega_{9}}{\Omega_{6}}\right| d
\end{array}\right.
$$

in order to enforce positive signs to springs and dashpots coefficients, as well as masses. It is worth noting that real parts of the LPM impedance matrix are second order parabolas in the nondimensional frequency $a_{0}$, while imaginary parts vary linearly. The non-dimensional parameters $\Omega_{i}(i=1 \ldots 15)$ of the LPM impedance matrix appearing in Equations (4) have to be calibrated to reproduce components of the soil-foundation impedance matrix (1) evaluated with dedicated software or analytical procedures (e.g. [22, 32, 38]).

Details of a linear least square calibration strategy that allows computing the best set of parameters of the lumped system can be found in [20]. In Figures 3 and 4 impedances of LPMs suitably calibrated with the mentioned procedure are shown with dashed lines. The adopted lumped system is able to well capture trends of impedances (both real and imaginary parts) in the frequency range $0 \div 10 \mathrm{~Hz}$.

\section{FORMULAS FOR ESTIMATING PARAMETERS $\Omega_{i}$ OF END-BEARING PILE GROUPS}

Closed-form empirical formulas to estimate parameters $\Omega_{i}$ of the LPMs representative of square r.c. end-bearing pile groups are presented in this section. These are calibrated starting from parameter values optimised with the procedure previously mentioned [20], by considering frequency dependent impedances evaluated with the model proposed by Dezi et al. [22]. The LPM parameters are calibrated to best fit the soil-foundation impedances in the frequency range $0 \div 10$ $\mathrm{Hz}$; considering the cut-off frequency issue previously addressed, formulas provide a reliable estimation of the LPM parameters for frequency ranging between the cut-off value and $10 \mathrm{~Hz}$.

A wide number of cases, representative of foundations with square layouts constituted by r.c. piles embedded in deformable homogeneous shallow soils from low to high stiffness and socked for 3 diameters in the underlying seismic bedrock (Figure 6a), are considered. In details, analysis cases are obtained by varying the number of piles $n$, the pile spacing-diameter ratio $s / d$, the pile length-diameter ratio $h / d$ and the stiffness ratio $E_{p} /\left(\rho_{s} V_{s}^{2}\right)$, where $E_{p}$ is the Young modulus of the pile material and $\rho_{s}$ and $V_{s}$ are the density and the shear wave velocity of the soil, respectively. Values attributed to the above non-dimensional parameters are listed in Figure 6b. For all cases, a constant Poisson's ratio $v=0.4$ and soil hysteretic damping ratios $\xi_{s}=0.05$ are assumed. Fixed values for the pile-soil density ratio $\rho_{p} / \rho_{s}$ are assumed for each $E_{p} /\left(\rho_{s} V_{s}^{2}\right)$ ratio since preliminary applications revealed that the influence of $\rho_{p} / \rho_{s}$ on impedances is limited (symbol " $\&$ " is used in Figure $6 \mathrm{~b}$ to couple the two parameters). Combination of parameters generates a total of 1470 analysis cases, which constitute the dataset from which formulas are calibrated.

It is worth noting that the optimization procedure is constrained to give positive definite matrices and positive masses, to guarantee the system implementation in commercial software for structural analysis (which generally do not allow introducing negative masses). Positivity of masses in some cases enforces solutions with null mass values; this circumstance is typical of impedance functions characterized by almost flat real parts or slightly increasing with frequency in the selected frequency range of calibration. (e.g. some translational or rotational terms of Figures 3 and 4). 


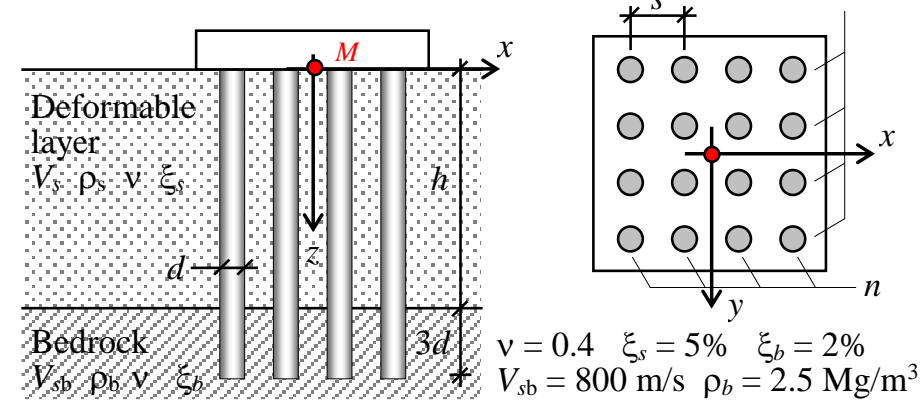

(a)

\begin{tabular}{c|c|c|cc}
$n$ & $\frac{s}{d}$ & $\frac{h}{d}$ & $\frac{E_{p}}{\rho_{s} V_{s}^{2}}$ & $\& \frac{\rho_{p}}{\rho_{s}}$ \\
\hline 1 & 2.0 & 12 & 2000 & 1.67 \\
2 & 2.5 & 14 & 1500 & 1.6058 \\
3 & 3.0 & 16 & 1000 & 1.5416 \\
4 & 3.5 & 18 & 442 & 1.4700 \\
5 & 4.0 & 20 & 300 & 1.3802 \\
& & 22 & 150 & 1.2854 \\
& & 24 & 94 & 1.2500 \\
& & 26 & & \\
& & 28 & &
\end{tabular}

(b)

Figure 6. (a) Scheme of investigated soil-foundation systems and (b) non-dimensional parameters generating the analysis cases

Expressions defined for the generic non-dimensional parameter $\Omega_{i}(i=1 \ldots 15)$ are reported below.

$$
\begin{aligned}
& \Omega_{1,4,5,6}=\alpha_{i}\left(\frac{s}{d}\right)^{\beta_{i}}\left(\frac{\rho_{p}}{\rho_{s}}\right)^{\chi_{i}}\left(\frac{E_{p}}{\rho_{s} V_{s}^{2}}\right)^{\delta_{i}} \\
& \Omega_{2,3,13,14,15}=\left(\frac{s}{d}\right)^{\alpha_{i}}\left(\frac{\rho_{p}}{\rho_{s}}\right)^{\beta_{i}}\left[\chi_{i}\left(\frac{E_{p}}{\rho_{s} V_{s}^{2}}\right)^{2}+\delta_{i} \frac{E_{p}}{\rho_{s} V_{s}^{2}}+\varepsilon_{i}\right] \\
& \Omega_{7}=\left(\alpha_{i}\left(\frac{s}{d}\right)^{\lambda}+\beta_{i}\right)\left[\chi_{i}\left(\frac{E_{p}}{\rho_{s} V_{s}^{2}}\right)^{2}+\delta_{i} \frac{E_{p}}{\rho_{s} V_{s}^{2}}+\varepsilon_{i}\right]\left(\frac{\rho_{p}}{\rho_{s}}\right)^{\phi_{i}}\left(\frac{L}{d}\right)^{\phi_{i}} \\
& \Omega_{8,9}=\left[\alpha_{i}\left(\frac{s}{d}\right)^{2 \lambda}+\beta_{i}\left(\frac{s}{d}\right)^{\lambda}+\chi_{i}\right]\left[\delta_{i}\left(\frac{E_{p}}{\rho_{s} V_{s}^{2}}\right)^{2}+\varepsilon_{i} \frac{E_{p}}{\rho_{s} V_{s}^{2}}+\phi_{i}\right]\left(\frac{\rho_{p}}{\rho_{s}}\right)^{\varphi_{i}}\left(\ln \frac{L}{d}\right)^{\gamma_{i}} \\
& \Omega_{10}=\left(\frac{s}{d}\right)^{\alpha_{i}}\left[\beta_{i}\left(\frac{E_{p}}{\rho_{s} V_{s}^{2}}\right)^{2}+\chi_{i} \frac{E_{p}}{\rho_{s} V_{s}^{2}}+\delta_{i}\right]\left(\frac{\rho_{p}}{\rho_{s}}\right)^{\varepsilon_{i}}\left(\frac{L}{d}\right)^{\phi_{i}} \\
& \Omega_{11,12}=\psi\left(\frac{s}{d}\right)^{\alpha_{i}}\left(\frac{\rho_{p}}{\rho_{s}}\right)^{\beta_{i}}\left(\frac{E_{p}}{\rho_{s} V_{s}^{2}}\right)^{\chi_{i}}\left[\delta_{i}\left(\frac{L}{d}\right)^{2}+\varepsilon_{i} \frac{L}{d}+\phi_{i}\right]
\end{aligned}
$$

In Equations (8c) and (8d)

$$
\begin{array}{lll}
\lambda=0 & \text { for } & n=1 \\
\lambda=1 & \text { for } & n>1
\end{array}
$$

while in Equation (8f) 
$\psi=0 \quad$ for $\quad \frac{E_{p}}{\rho_{s} V_{s}^{2}}<\kappa_{i}$

$\psi=1 \quad$ for $\quad \frac{E_{p}}{\rho_{s} V_{s}^{2}} \geq \kappa_{i}$

Constants appearing in Equations (8) and (10) are reported in Appendix I for foundations with different number of piles.

Figure 7 compares the non-dimensional parameters $\Omega_{i}$ optimised according to [20] with values obtained from the proposed formulas. Parameters $\Omega_{1}, \Omega_{3}, \Omega_{4}$ are reproduced closely, with errors lower than 30\% (dotted lines in Figure 7).
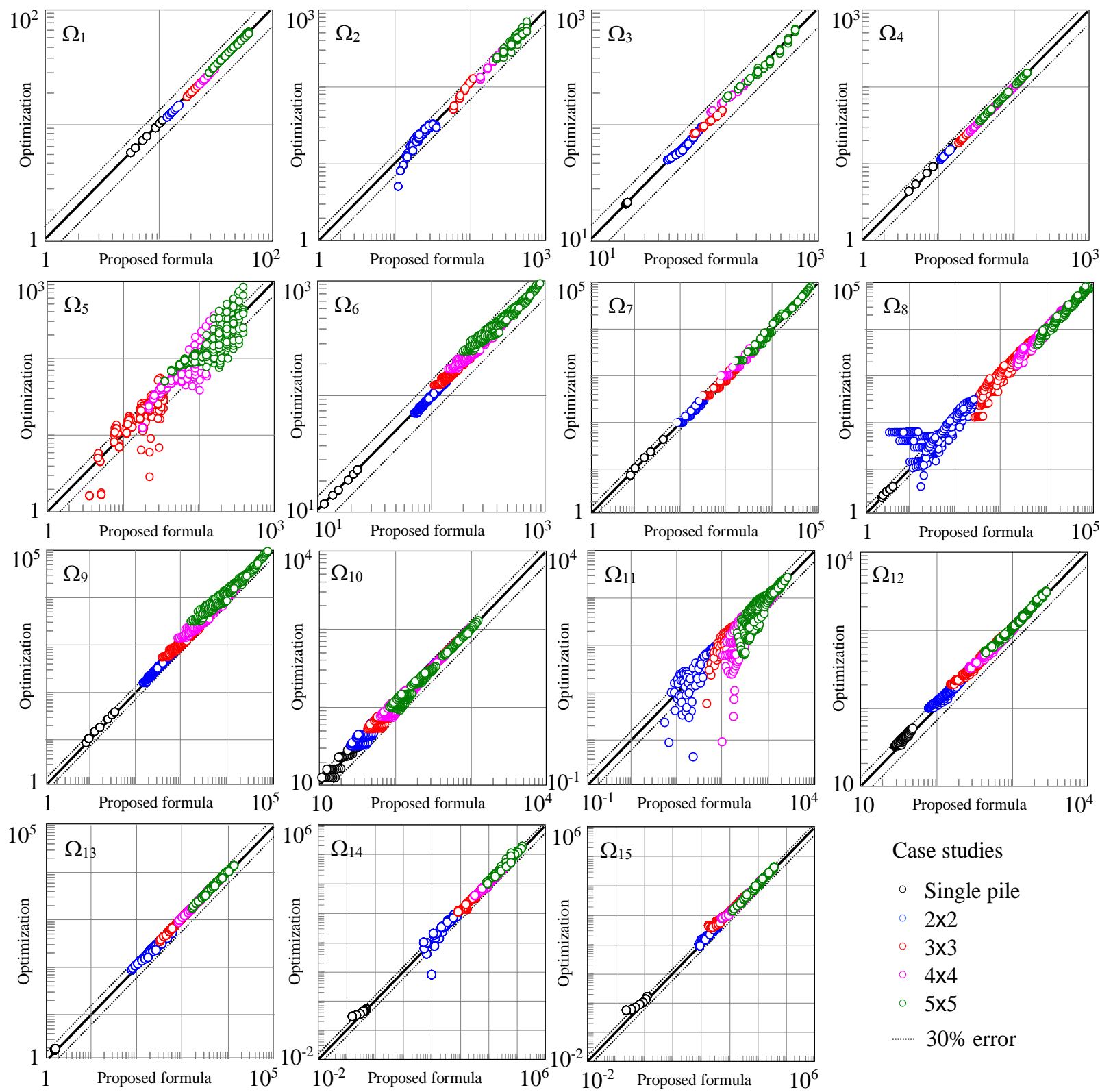

Figure 7. Comparisons between the optimized non-dimensional parameters of the LPMs and the proposed formulas 
On the contrary, parameters $\Omega_{5}, \Omega_{8}$ and $\Omega_{11}$, representative of mass terms, present errors sensibly higher; all the remaining parameters are characterised by errors of about $30 \%$ (with few exceptions). Errors relevant to masses are due to perturbations induced by the positivity condition in the LPM calibration procedure. The overall suitability of the proposed formulas in capturing the optimised parameters of the LPMs is quantified through the coefficients of determination (Rsquared coefficients) presented in Table 2. It should be noted that most of the computed R-squared parameters, including mean values obtained by averaging those of pile groups with different number of piles, are greater than 0.9 , excepting those relevant to $\Omega$. Furthermore, in a very high number of cases, the R-squared coefficients are higher than 0.95 . Finally, to provide a pictorial view of the formulas capabilities in predicting parameters of the optimised LPM, Figure 8 shows components $\Pi_{i}$ of the non-dimensional impedance matrix for the $4 \times 4$ pile groups with $s / d=2.5$,

$h / d=18$ and different $E_{p} /\left(\rho_{s} V_{s}^{2}\right)$ ratios, obtained from the dynamic analysis [22], from the LPM calibration (LPM_C) and from the proposed formulas (LPM_F). The proposed LPM, suitably calibrated, can approximate the soil-foundation dynamic stiffness very well in the optimization frequency range $0 \div 10 \mathrm{~Hz}$ with minor discrepancies affecting the imaginary parts at low frequencies, especially for the rotational $\left(\Pi_{r y}\right)$ component. Differences between the dynamic behaviour of LPM_C and LPM_F are overall very limited and mainly affect the torsional impedance $\left(\Pi_{r z}\right)$.

\section{APPLICATIONS OF THE PROPOSED FORMULAS}

Proposed formulas can be exploited to simplify the computational effort of seismic SSI analysis of structures, in the framework of the substructure approach, which classically requires the definition of the frequency-dependent compliant structural restraints and the evaluation of the FIM. Above quantities, usually obtained through frequency domain analysis of the soil-foundation system, have to be further elaborated in order to be used in time domain inertial SSI analysis of the superstructures: soil-foundation impedances must be reproduced by means of calibrated lumped systems and time histories of the FIM must be computed by the inverse Fourier transform. In this framework, proposed closed-form expressions directly provide parameters of the lumped system approximating the frequency-dependent impedance functions of the soil-foundation system, largely simplifying the overall procedure, especially if the free-field motion is assumed to be equal to the foundation input one.

Table 2. R-squared coefficients

\begin{tabular}{cccccccccccccccc}
\hline & $\Omega_{1}$ & $\Omega_{2}$ & $\Omega_{3}$ & $\Omega_{4}$ & $\Omega_{5}$ & $\Omega_{6}$ & $\Omega_{7}$ & $\Omega_{8}$ & $\Omega_{9}$ & $\Omega_{10}$ & $\Omega_{11}$ & $\Omega_{12}$ & $\Omega_{13}$ & $\Omega_{14}$ & $\Omega_{15}$ \\
\hline 1 & 1.00 & -- & 0.81 & 1.00 & --- & 1.00 & 1.00 & 1.00 & 1.00 & 0.99 & -- & 0.91 & 0.94 & 1.00 & 0.99 \\
$2 \times 2$ & 1.00 & 0.89 & 0.98 & 1.00 & --- & 1.00 & 0.99 & 0.94 & 0.99 & 1.00 & 0.98 & 0.97 & 1.00 & 0.94 & 0.97 \\
$3 \times 3$ & 1.00 & 0.93 & 0.99 & 1.00 & 0.79 & 1.00 & 0.99 & 0.94 & 0.99 & 1.00 & 0.97 & 0.98 & 1.00 & 0.99 & 0.99 \\
$4 \times 4$ & 1.00 & 0.97 & 0.99 & 1.00 & 0.72 & 1.00 & 0.99 & 0.98 & 0.99 & 1.00 & 0.93 & 0.99 & 1.00 & 0.99 & 1.00 \\
$5 \times 5$ & 1.00 & 0.97 & 0.99 & 1.00 & 0.72 & 1.00 & 0.99 & 0.98 & 0.99 & 1.00 & 0.93 & 0.99 & 1.00 & 0.99 & 1.00 \\
\hline Mean & $\mathbf{1 . 0 0}$ & $\mathbf{0 . 9 4}$ & $\mathbf{0 . 9 5}$ & $\mathbf{1 . 0 0}$ & $\mathbf{0 . 7 2}$ & $\mathbf{1 . 0 0}$ & $\mathbf{0 . 9 9}$ & $\mathbf{0 . 9 7}$ & $\mathbf{0 . 9 9}$ & $\mathbf{1 . 0 0}$ & $\mathbf{0 . 9 5}$ & $\mathbf{0 . 9 7}$ & $\mathbf{0 . 9 9}$ & $\mathbf{0 . 9 8}$ & $\mathbf{0 . 9 9}$ \\
\hline
\end{tabular}




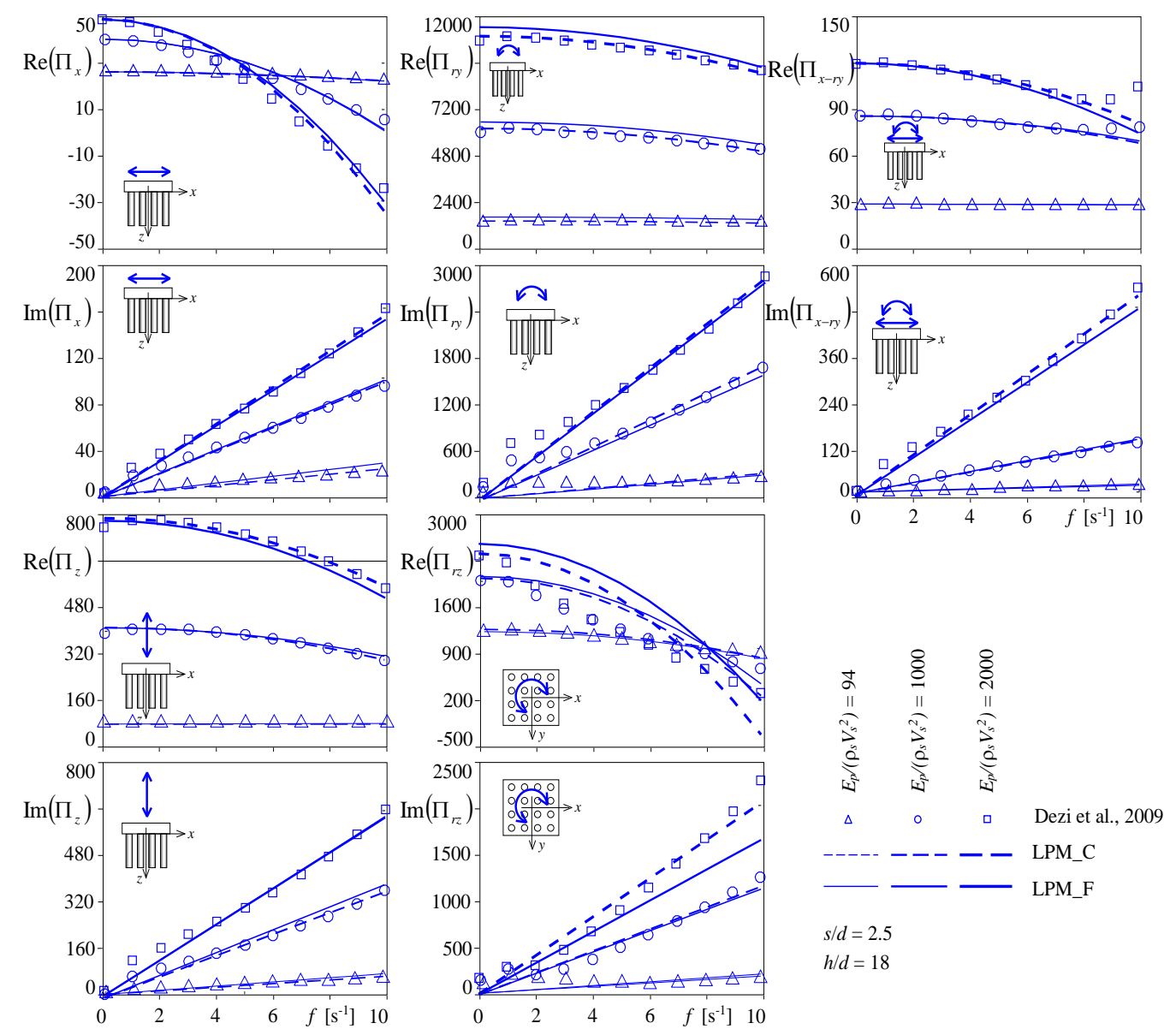

Figure 8. Impedances of $4 \times 4$ pile groups: comparisons of benchmarks with impedances of LPM_C and LPM_F

\subsection{Case Studies}

By assuming the FIM to coincide with the free-field motion [12, 13], formulas proposed in Section 4 are herein used to evaluate LPMs to perform SSI analyses of some bridge piers (Figure 9a) characterised by different fundamental periods. The scheme may be representative of the transverse response of multi-span bridges with decks not connected at the abutments in the transverse direction, or with dual load path mechanisms, for what concern the transverse seismic behaviour of inner piers [7]. Focusing on the deck and foundation displacements due to seismic actions in the $x$ direction (i.e. transverse bridge direction), piers are modelled with rigid elements and the elastic deformability is lumped at end rotational viscoelastic springs with stiffness $K_{\phi}$ and damping $C_{\phi}$ (Figure 9b). Pile and bent caps are assumed to be rigid, with masses $m_{c}$ and $m_{f}$, and moment of inertia $I_{c}$ and $I_{f}$, respectively. Furthermore, $m_{d}$ and $m_{p}$ are the masses of the bridge deck belonging to the pier and the mass of the pier, respectively, while $I_{d}$ is the deck moment of inertia. Finally, $h_{d}, h_{c}, h_{p}$ and $h_{f}$ are geometric parameters depicted in Figure 9b. Four piers (P1, P2, P3, $\mathrm{P} 4)$, characterised by properties reported in Table 3, are considered and assumed to be founded on $2 \times 2$ and $4 \times 4$ r.c. pile groups with $h / d=20$ and $s / d=3$, according to schemes of Figure 6a. Soft soil conditions (i.e $E_{p} /\left(\rho_{s} V_{s}^{2}\right)=1000$ and $\left.\rho_{p} / \rho_{s}=1.5416\right)$ are considered in order to enhance significance of SSI effects. 
With reference to the soil-foundation systems, mechanic and geometric dimensional parameters are obtained assuming $d=1 \mathrm{~m}, E_{p}=30000 \mathrm{MPa}$ and $\rho_{p}=2.5 \mathrm{t} / \mathrm{m}^{3}$. Finally, $5 \%$ structural damping is introduced in terms of stiffness proportional damping.

The response of the bridge piers on Compliant Base (CB) (Figure 9b) are computed considering both the LPM, with parameter obtained through the proposed formulas (CB-LPM), and the soilfoundation impedances (CB-IMP) resulting from the numerical procedure of Dezi et al. [22]. Furthermore, the response of piers on Fixed Base (FB) (Figure 9c) is also computed in order to evaluate significance of SSI effects on the bridge response and suitably weight discrepancies between the rigorous and simplified evaluation of the soil-foundation impedances.

Since accuracy of LPMs in reproducing impedances of the soil-foundation system may vary with frequency, each pier, characterised by a specific fundamental period, is analysed considering seismic actions with different frequency contents, selected from both the Europeans Strong motion Database (ESD) [39] and the Italian database Itaca (IT) [40].

Table 3. Superstructure and foundation parameters of bridge piers

\begin{tabular}{l|cccc}
\hline Superstructure & P1 & P2 & P3 & P4 \\
\hline Foundation & $\mathbf{2 \times 2}$ & $\mathbf{2 x 2}$ & $\mathbf{4 X 4}$ & $\mathbf{4 x 4}$ \\
\hline$m_{d}[\mathrm{t}]$ & 305.8 & 305.8 & 305.8 & 305.8 \\
$I_{d}\left[\mathrm{t} \mathrm{m}{ }^{2}\right]$ & 2466.6 & 2466.6 & 2466.6 & 2466.6 \\
$h_{d}[\mathrm{~m}]$ & 0.59 & 0.59 & 0.59 & 0.59 \\
$m_{c}[\mathrm{t}]$ & 88.3 & 88.3 & 88.3 & 88.3 \\
$I_{c}\left[\mathrm{t} \mathrm{m}{ }^{2}\right]$ & 426.6 & 426.6 & 426.6 & 426.6 \\
$h_{c}[\mathrm{~m}]$ & 1.80 & 1.80 & 1.80 & 1.80 \\
$m_{p}[\mathrm{t}]$ & 57.6 & 121.1 & 196.0 & 253.6 \\
$h_{p}[\mathrm{~m}]$ & 5.0 & 10.5 & 17.0 & 22.0 \\
$h_{f}[\mathrm{~m}]$ & 1.50 & 1.50 & 2.00 & 2.00 \\
$m_{f}[\mathrm{t}]$ & 95.6 & 95.6 & 326.2 & 326.2 \\
$I_{f}\left[\mathrm{t} \mathrm{m}{ }^{2}\right]$ & 217.0 & 217.0 & 1848.4 & 1848.4 \\
\hline$K_{\phi}[\mathrm{MN} / \mathrm{rad}]$ & 23067.6 & 10984.6 & 6784.6 & 5242.6 \\
\hline FB period $[\mathrm{s}]$ & 0.2001 & 0.50082 & 1.0076 & 1.4841 \\
\hline \multicolumn{5}{r}{}
\end{tabular}

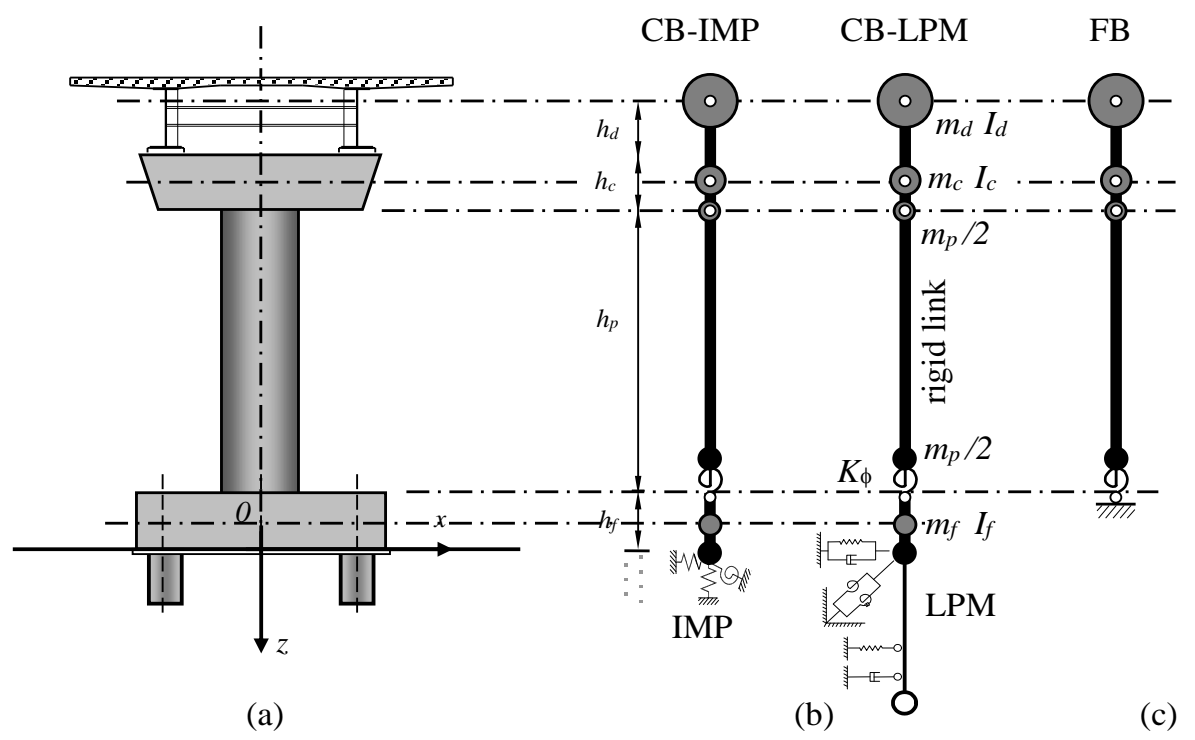

Figure 9. (a) Lateral view of one bridge pier; (b) CB models and (c) FB model 
The adopted earthquakes with high magnitude $\mathrm{M}_{\mathrm{w}}$ registered by stations on different soil types are reported in Table 4, while Figure 10 shows the relevant acceleration time histories and Fourier amplitude spectra from which the earthquakes frequency content can be evaluated. The seismic inputs of CB models implementing the actual frequency-dependent soil foundation impedances are evaluated rigorously considering the Dezi et al. model [22], which provides the FIM from a kinematic interaction analysis of the soil foundation system.

Table 4. Selected earthquakes

\begin{tabular}{cccccccc}
\hline ID & Earthquake & Station & Soil Type & Date & M $_{\mathbf{w}}$ & $\Delta[\mathbf{k m}]$ & PGA [g] $(\boldsymbol{x})$ \\
\hline ESD287 & Campano Lucano & ST93 & A & $23 / 11 / 80$ & 6.9 & 23 & 0.18 \\
ESD290 & Campano Lucano & ST96 & A & $23 / 11 / 80$ & 6.9 & 32 & 0.32 \\
ESD292 & Campano Lucano & ST98 & A & $23 / 11 / 80$ & 6.9 & 25 & 0.06 \\
ESD428 & Etolia & ST169 & A & $18 / 05 / 88$ & 5.3 & 23 & 0.18 \\
ESD593 & Umbria-Marche & ST60 & B & $26 / 09 / 97$ & 5.7 & 13 & 0.27 \\
ESD595 & Umbria-Marche & ST83 & B & $26 / 09 / 97$ & 5.7 & 25 & 0.04 \\
ESD601 & Umbria-Marche & ST224 & C & $26 / 09 / 97$ & 5.7 & 27 & 0.05 \\
ESD759 & Umbria-Marche & ST265 & B & $26 / 09 / 97$ & 5.7 & 32 & 0.04 \\
ESD4675 & South Iceland & ST2487 & A & $17 / 06 / 00$ & 6.5 & 13 & 0.13 \\
ESD6965 & Izmit (aftershock) & ST3270 & D & $13 / 09 / 99$ & 5.8 & 27 & 0.07 \\
ESD7089 & Pasinler & ST557 & A & $10 / 07 / 01$ & 5.4 & 32 & 0.02 \\
IT74 & Friuli & SRC0 & A & $11 / 09 / 76$ & 5.1 & 16 & 0.07 \\
\hline
\end{tabular}
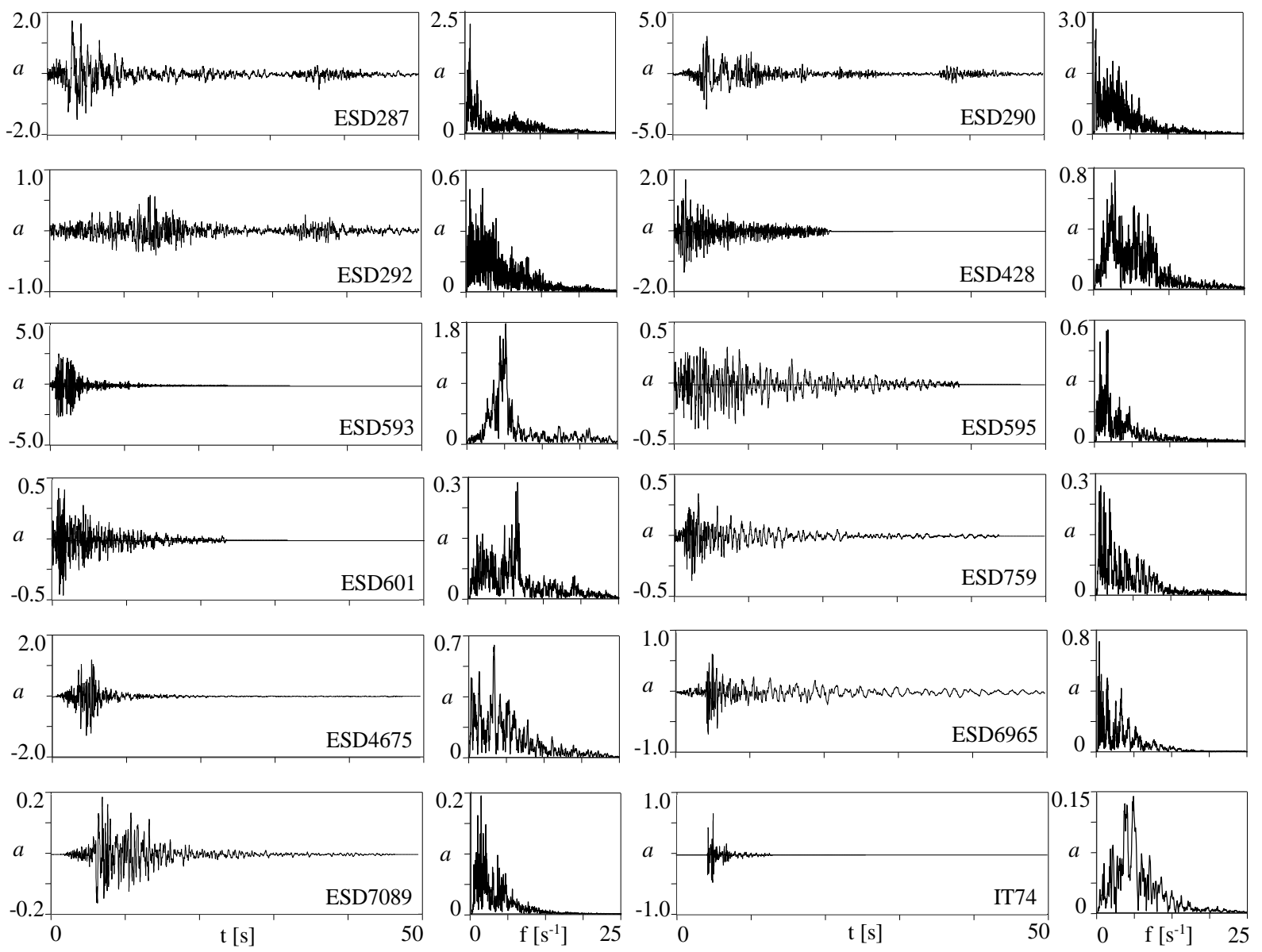

Figure 10. Acceleration time histories $\left[\mathrm{m} / \mathrm{s}^{2}\right]$ and Fourier amplitude spectra $\left[\mathrm{m} / \mathrm{s}^{2}\right]$ of the selected earthquakes 
On the contrary, the seismic inputs of the FB models and of CB models implementing LPMs, obtained through formulas of Section 4, are directly constituted by the selected free-field ground motions. It is worth mentioning that a rigorous evaluation of the FIM for the CB models implies the computation of the soil-foundation system kinematic factors, through which the translational and rotational components of the seismic action are evaluated.

\subsection{Main results}

Results of applications are presented in terms of bridge deck relative displacements (with respect to the foundation) and foundation displacements, comparing results obtained from the two $\mathrm{CB}$ models (CB-IMP, implementing the actual frequency-dependent soil foundation impedances, and CB-LPM, assembled according to the proposed formulas). Results of FB applications are considered to quantify significance of SSI effects, i.e. to weight importance of discrepancies between the rigorous (CB-IMP) and simplified (CB-LPM) approach.

Figure 11 shows the deck relative displacement of P2 obtained for two of the selected accelerograms (ESD287 and ESD428); results from FB and CB-IMP models are compared in the first row of graphs while comparisons of results from the CB models (i.e. CB-IMP and CB-LPM) are addressed in the second row of graphs. The simple observation of time histories suggests that SSI significantly affects the superstructure response, as expected in view of the superstructure stiffness (case study P2 is representative of a stiff superstructure), and that these effects can be reasonably captured by adopting a simplified analysis approach which foresees the application of the free-field motion, instead of the foundation input one, to a CB structure assembled exploiting the proposed formulas. The latter consideration is justified by the almost superimposed responses of the CB-IMP and CB-LPM models.

Figure 12 shows similar results for $\mathrm{P} 4$, which is representative of a slender superstructure. In this case, SSI is less pronounced and responses of CB-IMP and CB-LPM models perfectly match.
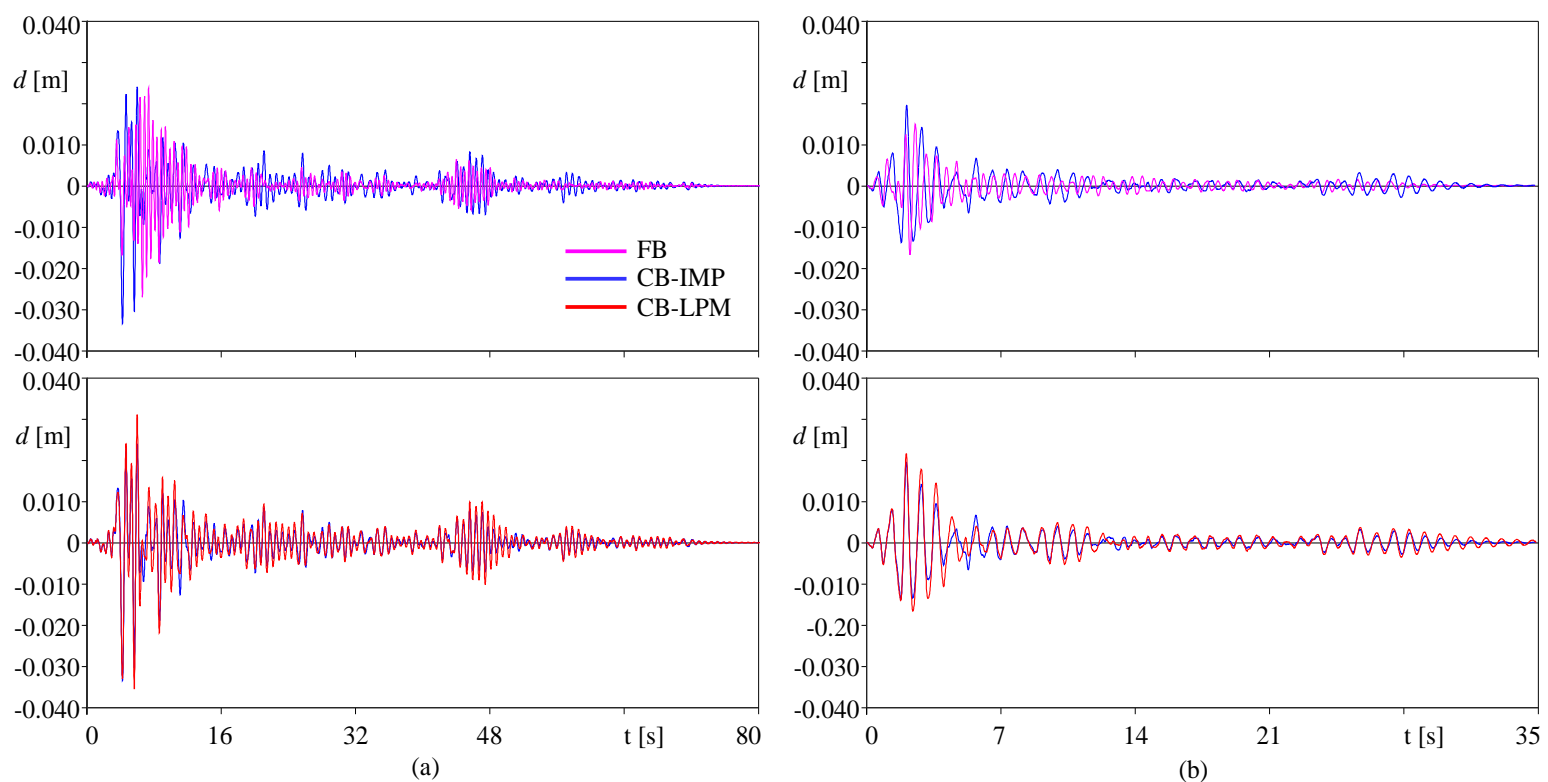

Figure 11. Deck displacements obtained from FB and CB models for (a) earthquake ESD287 and (b) earthquake ESD428 and for P2 

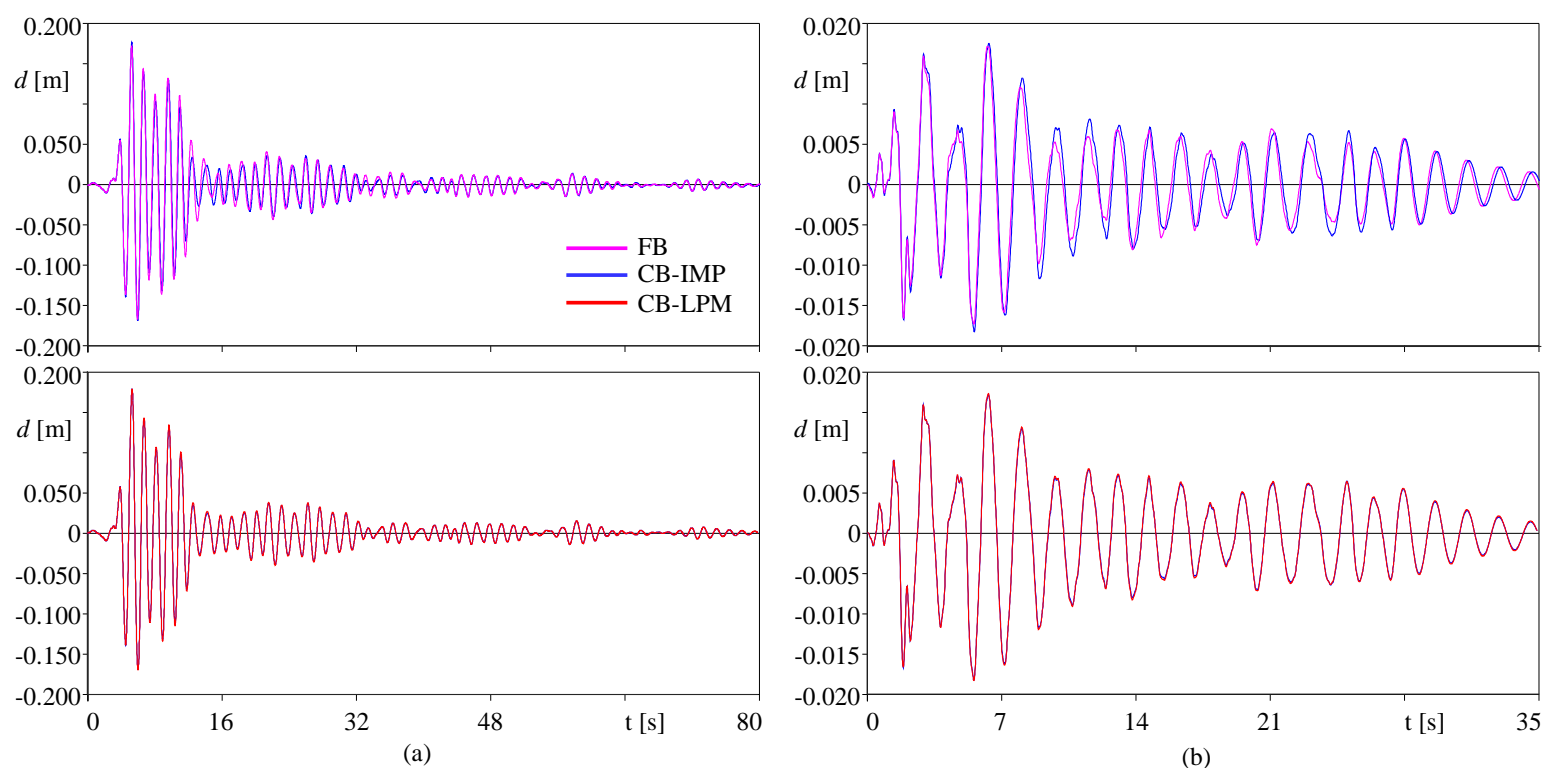

Figure 12. Deck displacements obtained from FB and CB models for (a) earthquake ESD287 and (b) earthquake ESD428 and for P4

In order to facilitate the presentation of results from all applications, and to quantitatively express the formulas efficiency, metrics proposed by Kavrakov et al. [41] are used in the sequel to compare time histories of displacements obtained from the different structural models. Metrics, quantifying discrepancies between two signals $x(t)$ and $y(t)$ in the time domain with respect to different properties, are expressed in the form:

$M_{i}(x, y)=e^{-\left|A_{i}(x, y)\right|}$

and assume values between 0 (completely discrepant signals) and 1 (no discrepancies between signals). In equation (11), subscript $i$ refers to the $i$-th particular property of the signals, for which the metric is constructed. Among those introduced in [41], the phase metric $M_{\varphi}$, the peak metric $M_{p}$, the root mean square metric $M_{r m s}$, the magnitude metric $M_{m}$, the wavelet metric $M_{w}$ and the frequency normalised wavelet metric $M_{w f}$ are herein considered. The phase metric accounts for the mean phase discrepancy between signals, with respect to a reference time delay $T_{C}$; the peak metric accounts for the difference in the maximum peak response while the root mean square metric quantify discrepancies of signals with respect to their average quantities. The magnitude metric accounts for discrepancies in the time-localized magnitude of the signals and is computed on the basis of the dynamic time warping algorithm [42]. Finally, the wavelet metric allows studying the overall signals discrepancies in the time-frequency plane while the frequency normalised wavelet metric allows to understand if the latter are due to the signal amplitudes or frequency content. Expressions of coefficients $A_{i}$ of above metrics are reported below for the sake of completeness; further details can be found in [41].

$$
A_{\varphi}=\frac{\arg \max _{t} x(t) * y(t)}{T_{C}}
$$

where $T_{C}$ is assumed to be the fundamental frequency of the pier;

$$
A_{p}=\frac{\max _{t}|x(t)|-\max _{t}|y(t)|}{\max _{t}|x(t)|}
$$


$A_{r m s}=\frac{\sqrt{\int_{t} x^{2}(t) d t}-\sqrt{\int_{t} y^{2}(t) d t}}{\sqrt{\int_{t} x^{2}(t) d t}}$

$A_{m}=\sqrt{\frac{\sum_{i=1}^{N_{w}}\left(x_{w}[i]-y_{w}[i]\right)^{2}}{\sum_{i=1}^{N_{w}}\left(x_{w}[i]\right)^{2}}}$

where $x_{w}$ and $y_{w}$ are the warped signals and $N_{w}$ is the number of warped steps;

$$
A_{w}=\frac{\iint_{a}|| W_{x}(a, t)|-| W_{y}(a, t)|| d t d a}{\iint_{a}\left|W_{x}(a, t)\right| d t d a}
$$

where $W_{x}$ and $W_{y}$ are the wavelet coefficients of signals $x$ and $y$, respectively, in the time-frequency plane, obtained by considering the Morlet wavelet, for which the scale $a$ is inversely proportional to the frequency;

$$
A_{w}=\frac{\iint_{a}\left|\frac{\left|W_{x}(a, t)\right|}{\max _{a}\left|W_{x}(a, t)\right|}-\frac{\left|W_{y}(a, t)\right|}{\max _{a}\left|W_{y}(a, t)\right|}\right| d t d a}{\iint_{a} \frac{\left|W_{x}(a, t)\right|}{\max _{a}\left|W_{x}(a, t)\right|} d t d a}
$$

Figure 13 refers to the deck relative displacements and shows comparisons in terms of above metrics for all applications (i.e. for all piers and earthquakes) adopting "radar graphs". In details, each radar refers to a specific pier and each line within the radar refers to one of the selected earthquakes. Association of each line to the relevant earthquake goes beyond the aim of the figure, which intends to provide a pictorial view of the overall discrepancies between the superstructure responses obtained from FB and CB models for input motions characterised by different frequency contents, magnitudes, and acceleration amplitudes. In this sense, blue lines quantify discrepancies between responses of CB-IMP and CB-LPM models, while red lines quantify discrepancies between responses from FB and CB-LPM models. With reference to red lines, it can be observed that SSI effects diminish sensibly by increasing the superstructure slenderness; greater effects can be observed for $\mathrm{P} 1$ for which metrics are all in in the range $0.35 \div 0.60$, with few exceptions relevant to $M_{p}$ and $M_{r m s}$. This implies that the response of the CB model is significantly different from that of the FB model, both in terms of amplitude and frequency content. For pier P2, discrepancies in terms of average quantities of signals $\left(M_{r m s}\right)$, maximum peak response $\left(M_{p}\right)$ and time lag $\left(\mathrm{M}_{\varphi}\right)$ diminish (metrics are mainly in the range $0.40 \div 0.90$ ) while differences in terms of time-localized magnitude $\left(M_{w}\right)$ and frequency content $\left(M_{w f}\right)$ remain important (metrics are in the range $0.35 \div 0.45)$. Piers P3 and P4 are less affected by SSI phenomena; both metrics quantifying discrepancies in terms of signal amplitude and frequency content are close to one $(0.80 \div 1.00)$.

The effectiveness of the proposed formulas in providing reliable lumped systems to simulate the actual soil-foundation impedances is quantified through metrics depicted with blue lines in Figure 13. 
For P1 and P2 the response of the CB-LPM model agree quite well with that obtained from the CB-IMP model, implementing the actual soil-foundation impedances, both in terms of signals amplitude and frequency content; the relevant metrics, indeed, vary between 0.75 and 1.00 , depending on the earthquake. Furthermore, discrepancies between the two CB models reduce significantly, passing from $\mathrm{P} 1$ to $\mathrm{P} 4$; in particular, for $\mathrm{P} 3$ and $\mathrm{P} 4$ the match is almost perfect.

With a similar approach, Figure 14 shows trends of the comparison metrics relevant to time histories of the foundation rotations, obtained from the CB-LPM and CB-IMP models.

(a)
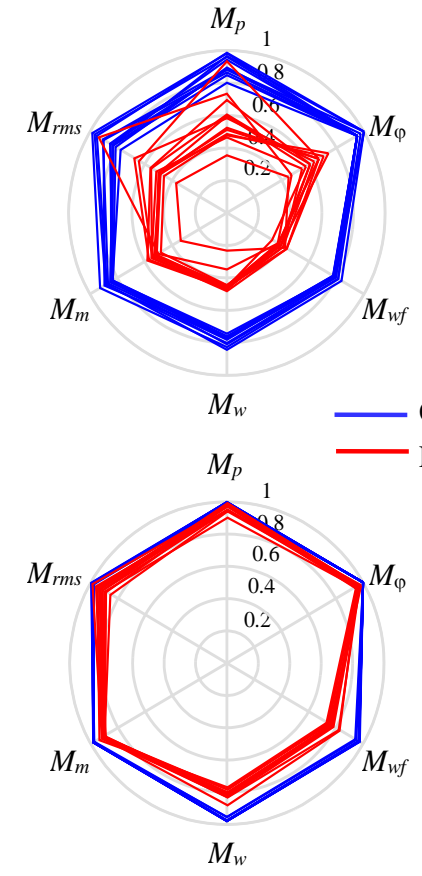

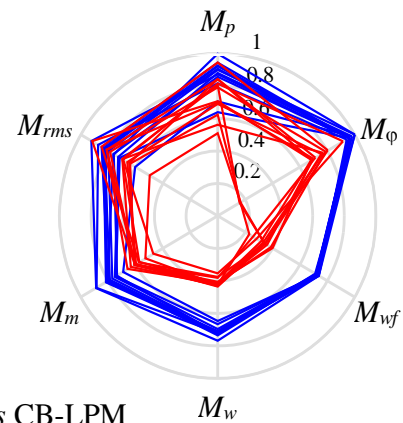

(b)

CB-IMP $v s$ CB-LPM $\quad M_{w}$

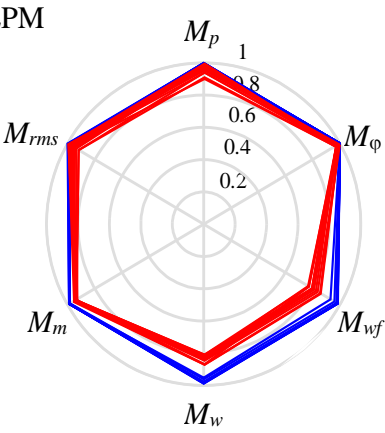

(d) (b)

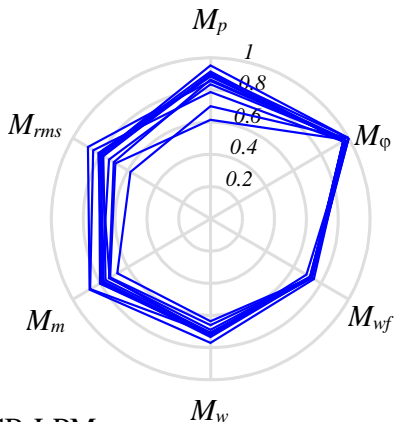

CB-IMP vs CB-LPM $\quad M_{w}$

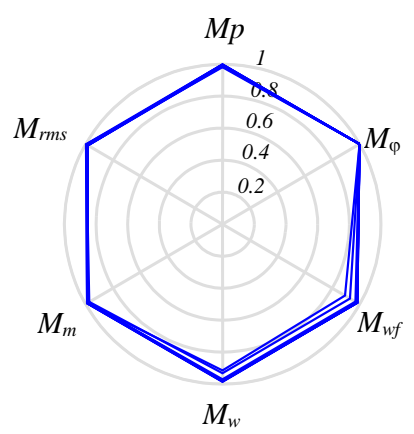

(d) P4

(c)

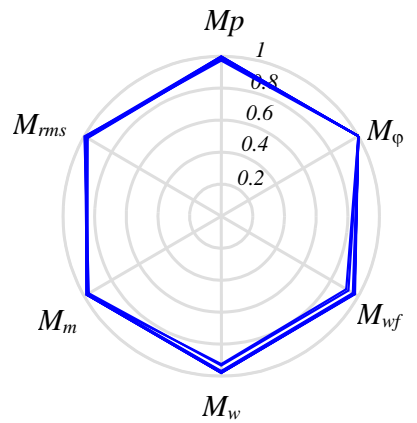

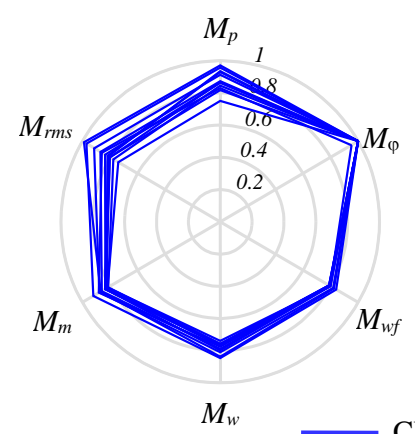

Figure 14. Comparison metrics for the foundation rotation: (a) P1, (b) P2, (c) P3 and (d) P4 
Previous considerations concerning deck displacements hold; overall the CB-LPM models are able to capture the response predicted with the more rigorous CB-IMP models with differences among them diminishing by increasing the superstructure slenderness.

\section{CONCLUSIONS}

With reference to end-bearing square pile groups, closed form expressions for evaluating parameters of the lumped system proposed by Carbonari et al. [20] have been identified and calibrated. The lumped model can be adopted in the framework of the sub-structure approach to perform time domain inertial analyses of superstructures considering the coupled rototranslational, vertical and torsional behaviour of the soil-foundation system. The system can be easily implemented in commercial software for structural analyses. Formulas are calibrated with a nonlinear least square procedure, based on data provided by an extensive non-dimensional parametric analysis, covering a wide number of cases representative of foundations constituted by r.c. piles embedded in deformable soils from low to high stiffness and socked in the underlying bedrock. Formulas, whose independent variables are the main geometrical and mechanical properties of the soil-foundation systems, are overall able to well capture all the parameters of the lumped system and can be readily adopted by engineers through simple spreadsheets to define compliant restraints to perform inertial soil-structure interaction analyses. Anyway, application of the proposed tools (i.e. analysis methodology, lumped parameter model and formulas) to practical situations requires an engineering judgment to reconcile the real case (i.e. stratified nonhomogenous soil deposit) with the academic one investigated in this paper and to care possible effects due to the cut-off issue, for those structures presenting a compliant base fundamental frequency lower or close to the cut-off one.

However, some applications of the proposed formulas in the framework of seismic soilstructure interaction analysis of bridges, demonstrate the potentials of the developed expressions in simplifying the analysis procedures while assuring a reliable prediction of the structural response, independently on the seismic input magnitude and frequency content.

\section{REFERENCES}

[1] Hassani N., Bararnia M., Amiri G.G. Effect of soil-structure interaction on inelastic displacement ratios of degrading structures. Soil Dynamics and Earthquake Engineering. 2018; 104:75-87.

[2] Ghandil M., Behnamfar F. Ductility demands of MRF structures on soft soils considering soil-structure interaction. Soil Dynamics and Earthquake Engineering. 2017; 92:203-214.

[3] Stefanidou S.P., Sextos A.G., Kotsoglou A.N., Lesgidis N., Kappos A.J. Soil-structure interaction effects in analysis of seismic fragility of bridges using an intensity-based ground motion selection procedure. Engineering Structures; 2017; 151:366-380.

[4] Behnamfar F., Banizadeh M. Effects of soil-structure interaction on distribution of seismic vulnerability in RC structures. Soil Dynamics and Earthquake Engineering. 2016; 80:7386.

[5] Anastasopoulos I., Sakellariadis L., Agalianos A. Seismic analysis of motorway bridges accounting for key structural components and nonlinear soil-structure interaction. Soil Dynamics and Earthquake Engineering. 2015; 78:127-141. 
[6] Carbonari S., Morici M., Dezi F, Gara F, Leoni G. Soil-structure interaction effects in single bridge piers founded on inclined pile groups. Soil Dynamics and Earthquake Engineering. 2017; 92:52-67.

[7] Capatti M.C., Tropeano G., Morici M, Carbonari S, Dezi F, Leoni G, Silvestri F. Implications of non-synchronous excitation induced by nonlinear site amplification and soil-structure interaction on the seismic response of multi-span bridges founded on piles. Bulletin of Earthquake Engineering. 2017; 15(11):4963-4995.

[8] Carbonari S., Dezi F. and Leoni G. Non-linear seismic behaviour of wall-frame dual systems accounting for soil-structure interactions. Earthquake Engineering and Structural Dynamics. 2012; 41(12):1651-1672.

[9] Elgamal A., Yan L., Yang Z., Conte J.P. Three-dimensional seismic response of Humboldt Bay bridge-foundation-ground system. Journal of Structural Engineering ASCE. 2008; 134(7):1165-76.

[10] Maheshwari B.K., Truman K.Z., El Naggar M.H., Gould P.L. Three-dimensional nonlinear analysis for seismic soil-pile-structure interaction. Soil Dynamics and Earthquake Engineering. 2004; 24:343-356.

[11] Wolf J.P., 1985. Dynamic Soil-Structure Interaction. Prentice-Hall, Inc., Englewood, N.J.

[12] Mamoon S.M., Banerjee P.K. Response of piles and pile groups to travelling SH waves. Earthquake Eng. Struct. Dynam. 1990; 19(4):597-610.

[13] Fan K., Gazetas G., Kaynia A., Kausel E., Ahmad S. Kinematic seismic response analysis of single piles and pile groups. Journal of the Geotechnical Engineering Division, ASCE. $1991 ; 117(12): 1860-79$.

[14] Wolf J.P., 1994. Foundation vibration analysis using simple physical models, PTR PrenticeHall.

[15] Wolf J.P. Consistent lumped-parameter models for unbounded soil: physical representation, Earthquake Eng. Struct. Dyn. 1991; 20:11-32.

[16] Jianguo X., Danmin W., Tieming F. A modified lumped parametric model for nonlinear soil-structure interaction analysis. Soil Dynamics and Earthquake Engineering. 1993; 12(5):273-282.

[17] Wang H., Liu W., Zhou D., Wang S., Du D. Lumped-parameter model of foundations based on complex Chebyshev polynomial fraction. Soil Dynamics and Earthquake Engineering. 2013; 50:192-203.

[18] Wang J., Zhou D., Liu W., Wang S. Nested lumped-parameter model for foundation with strongly frequency-dependent impedance. Journal of Earthquake Engineering. 2016; 20(6):975-991.

[19] Saitoh M. On the performance of lumped parameter models with gyro $\square$ mass elements for the impedance function of a pile $\square$ group supporting a single $\square$ degree $\square$ of $\square$ freedom system. Earthquake Engineering \& Structural Dynamics. 2012; 41(4):623-641.

[20] Carbonari S., Morici M., Dezi F, Leoni G. A lumped parameter model for time - domain inertial soil - structure interaction analysis of structures on pile foundations. Earthquake 
Engng Struct Dyn. 2018; 47(11):2147-2171.

[21] González F., Padrón L.A., Carbonari S., Morici M., Aznárez J.J., Dezi F., Leoni G. Seismic response of bridge piers on pile groups for different soil damping models and lumped parameter representations of the foundation. Earthquake Engng Struct Dyn. 2018;1-22. https://doi.org/10.1002/eqe.3137.

[22] Dezi F., Carbonari S., Morici M. A numerical model for the dynamic analysis of inclined pile groups. Earthquake Eng. Struct. Dynam. 2016; 45(1): 45-68.

[23] Dobry R., Vicente E., O'Rourke M.J., Roesset J.M. Horizontal Stiffness and Damping of Single Piles. Journal of Geotechnical Engineering Division, ASCE. 1982; 108(GT3):439459.

[24] Makris N., Gazetas G. Displacement phase differences in a harmonically oscillating pile. Geotechnique. 1993; 43(1):135-150.

[25] Gazetas G., Dobry R. Single radiation damping model for piles and footings. J. Engng. Mech., ASCE. 1984; 110(6):937-956.

[26] Gazetas G., Makris N. Dynamic pile-soil-pile interaction. Part I: analysis of axial vibration. Earthquake Engineering and Structural Dynamics. 1991; 20(2):115-132.

[27] Makris N, Gazetas G. Dynamic pile-soil-pile interaction. Part II: lateral and seismic response. Earthquake Engineering and Structural Dynamics. 1992; 21(2):145-162.

[28] Randolph M. F., Wroth C. P. Analysis of deformation of vertically loaded piles. J. Geotech. Engng, ASCE. 1978; 104(12):1465-1488.

[29] Baguelin F., Frank R. Theoretical studies of piles using the finite element method. Proc. Conf. Num. Meth. in Offshore Piling, London, Inst. Civ. Engrs. 1979; No. 11, 83- 91.

[30] Novak M. Piles under dynamic loads: State of the art. Proc. 2nd Int. Conf. on Recent Advances in Geotech. Earthquake Engng. and Soil Dynamics, St. Louis. 1991; 2433-2456.

[31] Mylonakis G. Elastodynamic model for large-diameter end-bearing shafts. Soils \& Foundations. 2001; 41(3):31-44.

[32] L.A. Padrón, J.J. Aznárez, O. Maeso. Dynamic analysis of piled foundations in stratified soils by a BEM-FEM model, Soil Dynamics and Earthquake Engineering. 2008; 28:333346.

[33] Zheng C., Ding X., Li P., Fu Q. Vertical impedance of an end-bearing pile in viscoelastic soil. Int. J. Numer. Anal. Meth. Geomech. 2015; 39:676-684.

[34] ANSYS Academic Research Mechanical, Release 18.1.

[35] Buckingham E. On physically similar systems; illustrations of the use of dimensional equations. Physical Review. 1914: 4(4):345-376.

[36] Kaljevic I., Saigal S., Ali a. An infinite boundary element formulation for threedimensional potential problems. International Journal for Numerical Methods in Engineering. 1992; 35(10):2079-2100.

[37] Carbonari S., Morici M., Dezi F., Leoni G. Analytical evaluation of impedances and kinematic response of inclined piles. Engineering Structures. 2016: 117:384-396. 
[38] Wang J, Lo S H, Zhou D. Effect of a forced harmonic vibration pile to its adjacent pile in layered elastic soil with double-shear model. Soil Dynamics and Earthquake Engineering. 2014; 67: 54-65.

[39] Ambraseys N., Smit P., Sigbjornsson R., Suhadolc P. and Margaris B. Internet-Site for European Strong-Motion Data, European Commission, Research-Directorate General, Environment and Climate Programme. 2002.

[40] Luzi L., Pacor F., Puglia R. Italian Accelerometric Archive v 2.3. Istituto Nazionale di Geofisica e Vulcanologia, Dipartimento della Protezione Civile Nazionale. 2017. doi: 10.13127/ITACA.2.3.

[41] Kavrakov I., Morgenthal G., Kareem A. Quantification of the influence of aerodynamic model assumptions for dynamic analyses of bridges. Proceedings of the $40^{\text {th }}$ IABSE Symposium. 2018; 19-21 September 2018, Nantes, France.

[42] Sarin H., Kokkolaras M., Hulbert G., Papalambros P., Barbat S., Yang R.-J. Comparing time-histories for validation of simulation models: error measures and metrics. Journal of Dynamic Systems, Measurement, and Control. 2010; 132, 061401.

\section{APPENDIX I}

Table A1. Parameters of Equations (8) and (10)

\begin{tabular}{|c|c|c|c|c|c|c|c|c|c|c|}
\hline$\Omega_{i}$ & $n$ & $\alpha$ & $\beta$ & $\chi$ & $\delta$ & $\varepsilon$ & $\phi$ & $\varphi$ & $\gamma$ & $\kappa$ \\
\hline \multirow{5}{*}{$\Omega_{1}$} & 1 & 2.20683 & 0 & 0.00145 & 0.21021 & - & - & - & - & - \\
\hline & 2 & 3.95051 & 0.20365 & -0.00023 & 0.21056 & - & - & - & - & - \\
\hline & 3 & 5.57664 & 0.26932 & -0.00149 & 0.21084 & - & - & - & - & - \\
\hline & 4 & 7.13818 & 0.30023 & 0.00065 & 0.21080 & - & - & - & - & - \\
\hline & 5 & 8.65519 & 0.31771 & 0.00557 & 0.21054 & - & - & - & - & - \\
\hline \multirow{5}{*}{$\Omega_{2}$} & 1 & 0 & -0.44848 & 0 & 0 & 0 & - & - & - & - \\
\hline & 2 & 0.72831 & 2.74226 & $-2.37 \mathrm{E}-07$ & 0.000231 & 3.78511 & - & - & - & - \\
\hline & 3 & 0.83961 & 1.08683 & $5.603 \mathrm{E}-07$ & -0.00284 & 27.03892 & - & - & - & - \\
\hline & 4 & 0.95976 & 0.19168 & 4.784E-07 & 0.00222 & 67.01696 & - & - & - & - \\
\hline & 5 & 1.02683 & -0.09726 & $-1.82 \mathrm{E}-06$ & 0.01657 & 115.9066 & - & - & - & - \\
\hline \multirow{5}{*}{$\Omega_{3}$} & 1 & 0 & -0.1808 & $1.669 \mathrm{E}-07$ & 0.000476 & 21.36234 & - & - & - & - \\
\hline & 2 & 0.54884 & 0.17127 & $-5.35 \mathrm{E}-07$ & 0.00593 & 30.29008 & - & - & - & - \\
\hline & 3 & 0.80035 & 0.47078 & $-1.83 \mathrm{E}-06$ & 0.01228 & 39.31741 & - & - & - & - \\
\hline & 4 & 0.96114 & 0.74962 & $-2.04 \mathrm{E}-06$ & 0.0154 & 48.6382 & - & - & - & - \\
\hline & 5 & 1.08628 & 0.76012 & $-3.07 \mathrm{E}-06$ & 0.02388 & 60.16417 & - & - & - & - \\
\hline \multirow{5}{*}{$\Omega_{4}$} & 1 & -0.49282 & 0 & 0.00158 & 0.47346 & - & - & - & - & - \\
\hline & 2 & -1.15308 & 0.1359 & -0.00232 & 0.47388 & - & - & - & - & - \\
\hline & 3 & -1.899 & 0.18094 & 0.00154 & 0.47356 & - & - & - & - & - \\
\hline & 4 & -2.71322 & 0.20184 & 0.01592 & 0.47244 & - & - & - & - & - \\
\hline & 5 & -3.58332 & 0.21328 & 0.03704 & 0.47094 & - & - & - & - & - \\
\hline \multirow{5}{*}{$\Omega_{5}$} & 1 & 0 & 0 & 0 & 0 & - & - & - & - & - \\
\hline & 2 & 0 & 0 & 0 & 0 & - & - & - & - & - \\
\hline & 3 & -0.60842 & -0.23992 & 4.53695 & 0.24911 & - & - & - & - & - \\
\hline & 4 & -2.27738 & 0.78598 & 3.8906 & 0.15478 & - & - & - & - & - \\
\hline & 5 & -2.79472 & 1.06496 & 3.2542 & 0.24101 & - & - & - & - & - \\
\hline \multirow{5}{*}{$\Omega_{6}$} & 1 & 3.22514 & 0 & 0.30245 & 0.23005 & - & - & - & - & - \\
\hline & 2 & 3.97101 & 0.48106 & 0.38126 & 0.3291 & - & - & - & - & - \\
\hline & 3 & 5.31738 & 0.66483 & 0.30408 & 0.38741 & - & - & - & - & - \\
\hline & 4 & 7.53143 & 0.77205 & 0.47104 & 0.39779 & - & - & - & - & - \\
\hline & 5 & 9.72955 & 0.84712 & 0.39294 & 0.42266 & - & - & - & - & - \\
\hline
\end{tabular}




\begin{tabular}{|c|c|c|c|c|c|c|c|c|c|c|}
\hline$\Omega_{i}$ & $n$ & $\alpha$ & $\beta$ & $\chi$ & $\delta$ & $\varepsilon$ & $\phi$ & $\varphi$ & $\gamma$ & $\kappa$ \\
\hline \multirow{5}{*}{$\Omega_{7}$} & 1 & $5.6625 \mathrm{E}-05$ & $5.77 \mathrm{E}-05$ & -0.03354 & 232.7635 & 30019.93 & 0.88453 & -0.00040 & - & - \\
\hline & 2 & 0.00077919 & -0.00076 & -0.06386 & 433.5887 & 171694.2 & 1.75513 & -0.3441 & - & - \\
\hline & 3 & 0.00282 & -0.00358 & -0.12227 & 1037.128 & 344937.2 & 1.40658 & -0.44029 & - & - \\
\hline & 4 & 0.00694 & -0.00945 & -0.16538 & 1691.237 & 471922.6 & 1.13963 & -0.48307 & - & - \\
\hline & 5 & 0.01353 & -0.01902 & -0.19653 & 2367.728 & 571263.4 & 0.94006 & -0.5009 & - & - \\
\hline \multirow{5}{*}{$\Omega_{8}$} & 1 & $-2.127 \mathrm{E}-07$ & $-2.13 \mathrm{E}-07$ & $-2.13 \mathrm{E}-07$ & 0.18159 & -485.846 & -2091490 & 2.07403 & 0.01892 & - \\
\hline & 2 & 0.00033337 & -0.00109 & 0.00103 & -0.0226 & 79.50082 & -2438.37688 & -3.48682 & 2.31184 & - \\
\hline & 3 & 0.00534 & -0.01508 & 0.0127 & -0.28697 & 1334.937 & -14314.0097 & -7.9606 & 1.35155 & - \\
\hline & 4 & 0.00533 & -0.01465 & 0.01223 & 0.01035 & -43.42026 & 140587.3635 & 1.29069 & 1.07711 & - \\
\hline & 5 & 0.01998 & -0.05565 & 0.0477 & 0.01182 & -38.2927 & 191842.0915 & 0.33118 & 0.91193 & - \\
\hline \multirow{5}{*}{$\Omega_{9}$} & 1 & $2.9766 \mathrm{E}-06$ & $2.98 \mathrm{E}-06$ & $2.976 \mathrm{E}-06$ & -0.12533 & 521.4217 & 435223.6453 & 2.60335 & 0.00794 & - \\
\hline & 2 & 0.00017926 & -0.00015 & 0.00065 & -0.00267 & 19.15515 & 59971.3804 & 0.73802 & 0.57976 & - \\
\hline & 3 & 0.00096233 & -0.00285 & 0.00351 & -0.00575 & 27.28366 & 53174.85506 & 1.65464 & 1.09161 & - \\
\hline & 4 & 0.00312 & -0.01146 & 0.01319 & -0.00363 & 17.37703 & 39454.39976 & 2.68146 & 1.48159 & - \\
\hline & 5 & 0.00864 & -0.03444 & 0.03942 & -0.00291 & 15.06353 & 32917.26453 & 3.01846 & 1.69822 & - \\
\hline \multirow{5}{*}{$\Omega_{10}$} & 1 & 0 & $-1,03 \mathrm{E}-05$ & 0,0848421 & 28,68086 & 1,46576 & $-0,45835$ & - & - & - \\
\hline & 2 & 0,08192 & $-2,38 \mathrm{E}-05$ & 0,4290812 & 85,40291 & 0,57299 & $-0,51224$ & - & - & - \\
\hline & 3 & 0,12816 & $-3,09 \mathrm{E}-05$ & 0,7208385 & 116,5395 & 0,45263 & $-0,47394$ & - & - & - \\
\hline & 4 & 0,16591 & $-3,03 \mathrm{E}-05$ & $9,08 \mathrm{E}-01$ & 133,7845 & 0,37313 & $-0,41934$ & - & - & - \\
\hline & 5 & 0,19934 & $-2,47 \mathrm{E}-05$ & $1,01 \mathrm{E}+00$ & 143,3302 & 0,31734 & $-0,36691$ & - & - & - \\
\hline \multirow{5}{*}{$\Omega_{11}$} & 1 & 0 & 0 & 0 & 0 & 0 & 0 & - & - & 2000 \\
\hline & 2 & $9,69 \mathrm{E}-01$ & $-19,6$ & $3,07 \mathrm{E}+00$ & $-1,67 \mathrm{E}-07$ & 9,87E-06 & $-7,6516 \mathrm{E}-05$ & - & - & 442 \\
\hline & 3 & 1,06354 & $-3,38$ & 0,88332 & $-0,001261$ & $8,74 \mathrm{E}-02$ & $-0,45599353$ & - & - & 300 \\
\hline & 4 & 1,04904 & $-0,511$ & 5,99E-01 & $-0,002421$ & $2,33 \mathrm{E}-01$ & 0,06260198 & - & - & 0 \\
\hline & 5 & 1,03754 & 0,60216 & 0,41476 & $-0,001695$ & 4,65E-01 & 7,8268823 & - & - & 0 \\
\hline \multirow{5}{*}{$\Omega_{12}$} & 1 & 0 & 0,59049 & 0,05557 & $-0,000792$ & 0,30204318 & 16,4602273 & - & - & 0 \\
\hline & 2 & 0,61742 & 0,47699 & 0,18137 & 0,010835 & $-0,2495260$ & 22,687036 & - & - & 0 \\
\hline & 3 & 0,87509 & 0,21319 & 0,28866 & 0,013036 & $-0,4340227$ & 26,3905513 & - & - & 0 \\
\hline & 4 & 0,97493 & 0,20027 & 0,33256 & 0,013930 & $-0,5180498$ & 35,3765775 & - & - & 0 \\
\hline & 5 & 1,02386 & 0,15193 & 0,35794 & 0,011682 & $-4,36 \mathrm{E}-01$ & $4,68 \mathrm{E}+01$ & - & - & 0 \\
\hline \multirow{5}{*}{$\Omega_{13}$} & 1 & 0 & 0 & 0 & 0 & 0 & - & - & - & - \\
\hline & 2 & 1.75344 & 1.34909 & $-1.41 \mathrm{E}-06$ & 0.00499 & 16.00872 & - & - & - & - \\
\hline & 3 & 1.93871 & 1.36806 & $-5.30 \mathrm{E}-06$ & 0.01874 & 59.18202 & - & - & - & - \\
\hline & 4 & 2.04008 & 1.37436 & -0.000013 & 0.04497 & 141.34578 & - & - & - & - \\
\hline & 5 & 2.10388 & 1.37774 & $-2.47 \mathrm{E}-05$ & 0.08709 & 273.41737 & - & - & - & - \\
\hline \multirow{5}{*}{$\Omega_{14}$} & 1 & 0 & 0 & 0 & 0 & 0 & - & - & - & - \\
\hline & 2 & 3.43807 & -8.44519 & $-9.22 \mathrm{E}-05$ & 0.39579 & -4.61503 & - & - & - & - \\
\hline & 3 & 2.87355 & -1.05179 & $3.562 \mathrm{E}-05$ & -0.13316 & 322.13418 & - & - & - & - \\
\hline & 4 & 2.74287 & -2.34447 & 0.000284 & -0.94663 & 2353.98912 & - & - & - & - \\
\hline & 5 & 2.69686 & -2.72946 & 0.00152 & -3.97363 & 7635.85437 & - & - & - & - \\
\hline \multirow{5}{*}{$\Omega_{15}$} & 1 & 0 & 0 & 0 & 0 & 0 & - & - & - & - \\
\hline & 2 & 1.94311 & -1.92629 & $2.074 \mathrm{E}-06$ & 0.01241 & 39.82764 & - & - & - & - \\
\hline & 3 & 2.83271 & 0.5482 & $-3.39 \mathrm{E}-06$ & 0.02146 & 23.50052 & - & - & - & - \\
\hline & 4 & 3.1257 & 2.2111 & $-7.73 \mathrm{E}-06$ & 0.02901 & 32.50647 & - & - & - & - \\
\hline & 5 & 3.17766 & 2.70347 & $-1.80 \mathrm{E}-05$ & 0.05597 & 72.5556 & - & - & - & - \\
\hline
\end{tabular}

